\begin{tabular}{|c|c|c|c|c|c|}
\hline MUNIBE Antropologia-Arkeologia & $n^{\circ} 67$ & $105-126$ & DONOSTIA & 2016 & ISSN 1132-2217 • eISSN 2172-4555 \\
\hline
\end{tabular}

\title{
La cerámica de la Edad del Bronce en el yacimiento de El Portalón de Cueva Mayor (Sierra de Atapuerca, Burgos, España)
}

\author{
Bronze Age pottery from El Portalón de Cueva Mayor site \\ (Atapuerca, Burgos, Spain)
}

PALABRAS CLAVES: Holoceno, cerámica, tipología, tecnología, morfología.

GAKO-HITZAK: Holozenoa, zeramika, tipologia, teknologia, morfologia.

KEY WORDS: Holocene; pottery, typology, technology, morphology.

\author{
PÉREZ-ROMERO, A. ${ }^{(1)}$, ALDAY, A..$^{(2)}$, IRIARTE, E.(1), FRANCÉS-NEGRO, M.(1), GALINDO-PELLICENA, M.A.(3) \\ ÁLVAREZ-FERNÁNDEZ, A. ${ }^{(1)}$, JUEZ, L.(1), ARSUAGA, J.L. ${ }^{(3,4)}$ y CARRETERO, J.M..$^{(1,3)}$
}

\section{RESUMEN}

Este trabajo estudia la amplia colección cerámica de la Edad del Bronce recuperada en El Portalón de Cueva Mayor (Sierra de Atapuerca, Burgos). La muestra procede de tres intervenciones arqueológicas modernas cuyos resultados se resumen aquí, por primera vez, de manera conjunta, sintetizando los caracteres sedimentarios y culturales ofrecidos por los respectivos responsables de los trabajos de campo. Se caracteriza tecno-tipológicamente la colección, la relación forma-función de los recipientes, el modelo productivo y las manifestaciones simbólicas propias de algunas producciones.

El conjunto alfarero de El Portalón muestra una llamativa homogeneidad con independencia de su pertenencia a un nivel sedimentario y fase cultural. Desde el punto de vista alfarero se detecta una continuidad técnica y formal durante el Bronce antiguo y medio en el porcentaje de tipos y variantes, el tratamiento de las superficies, la profusión y estilo de las decoraciones y en la cocción. Es decir, no hay variaron en los patrones de producción a lo largo de los 700 años que representa el paquete sedimentario del Bronce en este Yacimiento.

\section{LABURPENA}

Lan honek El Portalón de Cueva Mayorren (Atapuerca mendilerroa, Burgos) berreskuratutako Brontze Aroko bilduma zeramiko handia aztertzen du. Lagina hiru esku-hartze arkeologiko modernotatik ateratakoa da eta horien guztien emaitzak lehen aldiz hemen daude laburbilduta, landa-lanetako arduradunek eskainitako ezaugarri sedimentarioak eta kulturalak laburtuta. Ezaugarri tekno-tipologikoei dagokienez, hauek nabarmentzen dira: bilduma, ontzien formaren eta funtzioaren arteko erlazioa, produkzio-eredua eta produkzio batzuen adierazpen sinbolikoak.

El Portalóneko eltzegintzako multzoak homogeneotasun ikusgarria du nahiz eta maila sedimentario eta fase kultural jakin batekoa izan. Eltzegintzaren ikuspegitik, mota eta barianteen ehunekoari, gainazalen tratamenduari, apaingarrien estiloari eta ugaritasunari, eta erreketari dagokienez antzinako Brontzeko eta Brontze ertaineko jarraipen teknikoa eta formala ikus daiteke. Hau da, aztarnategi horretako Brontze Aroko pakete sedimentarioak jasotzen duen 700 urteko epean ez da produkzio-ereduetan inolako aldaketarik ikusten.

\section{ABSTRACT}

This paper studies the extensive pottery collection of the Bronze Age recovered at the site of El Portalón of Cueva Mayor (Sierra de Atapuerca, Burgos). The studied sample comes from three modern archaeological interventions whose results are summarized here for the first time putting together and synthesizing the sedimentary and cultural characteristics offered by the respective field works. We study techno-typologically the pottery collection, the relationship between form and function of the containers, the production model and the characteristics of decorative symbolic manifestations.

The Bronze Age pottery set from El Portalón shows a striking homogeneity regardless their sedimentary level and cultural phase. Technically and formally we detect continuity during the Early and Middle Bronze Age in the proportions of type elements, their variants, the surface treatments, the profusion and style of decorations and the kind of bake. That is, there is no change in production patterns over the 700 years represented by the sedimentary Bronze package at this site.

\footnotetext{
(1) Laboratorio de Evolución Humana, Departamento de Ciencias Históricas y Geografía, Universidad de Bugros, edificio I+D+I, Plaza de Misael Bañuelos s/n 09001, Burgos, Spain. apromero@ubu.es; eiriarte@ubu.es; martafn86@gmail.com; ljuez76@gmail.com; jmcarre@ubu.es (2) Departamento de Geografía e Historia, Universidad del País Vasco, C/ Tomás y Vicente s/n, 01006 Vitoria, Spain. a.alday@ehu.es. (3) Centro Mixto UCM-ISCIII de Evolución y Comportamiento Humanos. C/ Monforte de Lemos 5, pabellón 14, 28029 Madrid, Spain, mariangape79@hotmail.com; jlarsuaga@isciii.es

(4) Departamento de Paleontología. Facultad de Ciencias Geológicas Universidad Complutense de Madrid, 28040 Madrid, Spain. jlarsuaga@isciii.es
} 


\section{1.- INTRODUCTION}

La Sierra de Atapuerca es bien conocida por sus yacimientos pleistocenos (ARSUAGA et al., 1997, 2014, 2015; BERMÚDEZ DE CASTRO et al., 1999, 2011, 2015) pero también por presentar un rico y variado registro del Holoceno (CLARK et al., 1979; APELLÁNIZ y DOMINGO, 1987; CARRETERO et al., 2008; ALDAY et al., 2011, 2015; PÉREZ ROMERO et al., 2010, 2013, 2015 (a y b); VERGÉS et al., 2002, 2008).

En su interior se desarrolla un sistema Kárstico de unos $3.700 \mathrm{~m}$ de longitud, conocido como Cueva Mayor-Cueva del Silo (ORTEGA, 2009) que contiene abundantes depósitos arqueológicos, variados en su funcionalidad y de especial interés para el estudio de la prehistoria europea. Entre los depósitos holocenos de este sistema destaca el conocido como El Portalón, que es la entrada actual al sistema kárstico, donde se ha documentado una ocupación humana prolongada desde el final del Pleistoceno superior hasta la actualidad (Figura 1).
La secuencia estratigráfica supera los $10 \mathrm{~m}$ de potencia y está subdividida en 11 niveles estratigráficos agrupados en dos grandes unidades sedimentarias, una del Pleistoceno superior y otra del Holoceno (CARRETERO et al., 2008). Esta última consta de diez niveles cuyas filiaciones culturales basadas en los registros materiales y apoyadas por una larga serie radiocronológica, evidencian ocupaciones de la Edad Media, Época Romana, Edad del Hierro I (Niveles, 0, 1 y 2), Edad del Bronce medio e inicial (Niveles 3,4 y 5), Calcolítico (Niveles 6, 7 y 8) y Neolítico/Mesolítico (Nivel 9) (CARRETERO et al., 2008), (Figura 2).

Las excavaciones realizadas en El Portalón con anterioridad a las de nuestro equipo (EIA) se deben a G.A. Clark, L.G. Strauss y JL Uribarri en 1972, y a Juan María Apellániz y su equipo entre 1973 y 1983. Entre 1983 y 1999 el yacimiento permaneció inactivo, reiniciándose las excavaciones por parte del EIA en el año 2000, trabajos que continúan en la actualidad. Todos estos trabajos, a pesar de sus diferentes criterios de ordenación cultural, sirven para mostrar un uso activo y

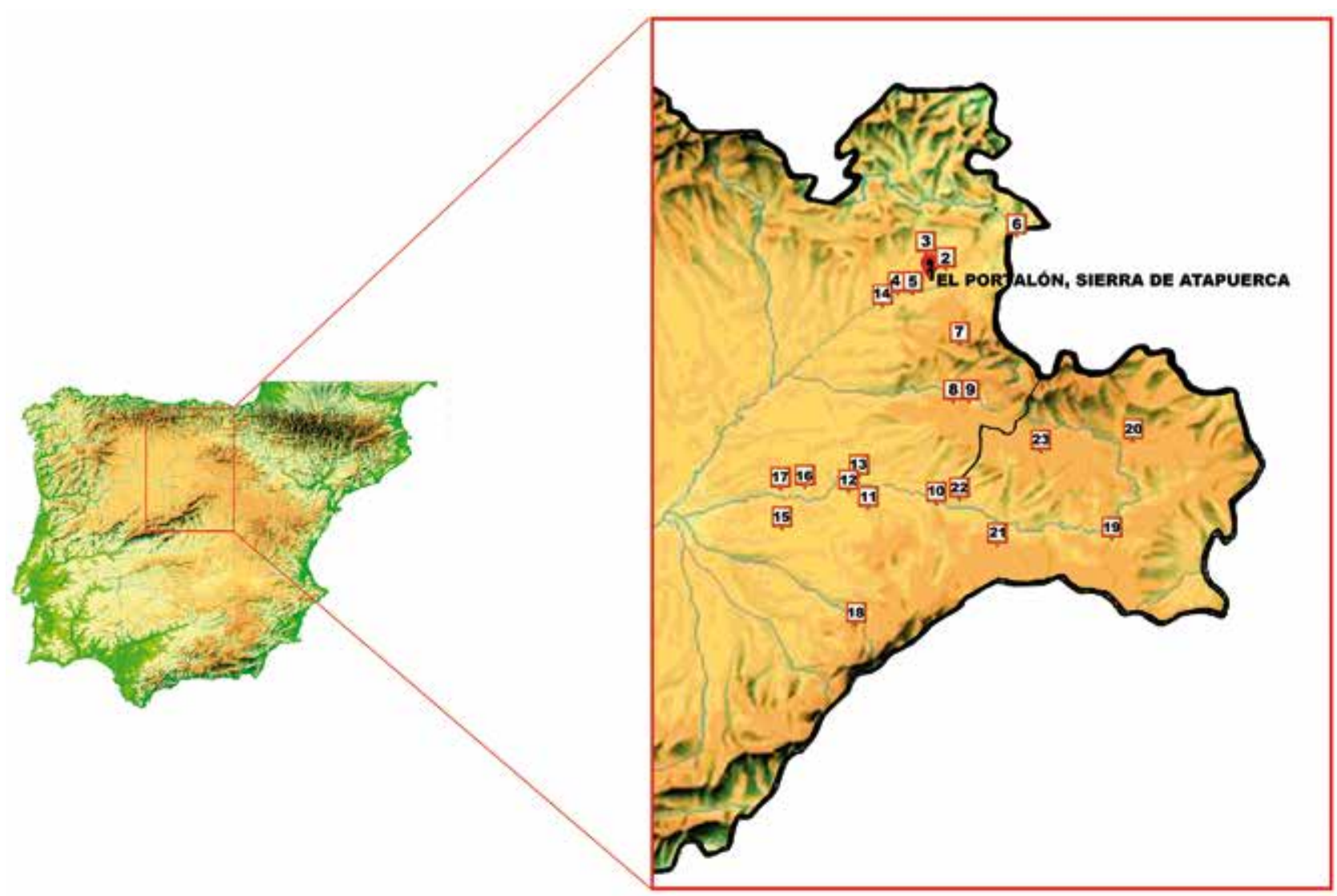

Fig. 1. Localización de los principales yacimientos de la Edad del Bronce situados en el sector oriental de la Meseta norte mencionados en este estudio / Location of the main Bronze Age sites in the Eastern area of the Northern plateau mentioned in this study: Burgos 1) El Portalón de Cueva Mayor; 2) El Mirador; 3) La Cueva de la Revilla; 4) Las Veguillas; 5) La Casa de la Villa; 6) Desfiladero de Pancorbo; 7) La Aceña); 8) La Cueva de San García; 9) El castro de la Yecla; 10) Pico Romero I; 11) Las Empedradas; 12 ) Carrasalinera; 13) El Cerro; 14) Los Cascajos. Valladolid: 15) El Carrizal; 16) Pico Castro; 17) El Cementerio-El Prado. Segovia: 18) La Cueva de Arevalillo. Soria: 19) El Parpantique; 20) La Cueva del Asno; 21) Los Torojones; 21) El Pico de los Cotorros; 22) Cueva Maja 


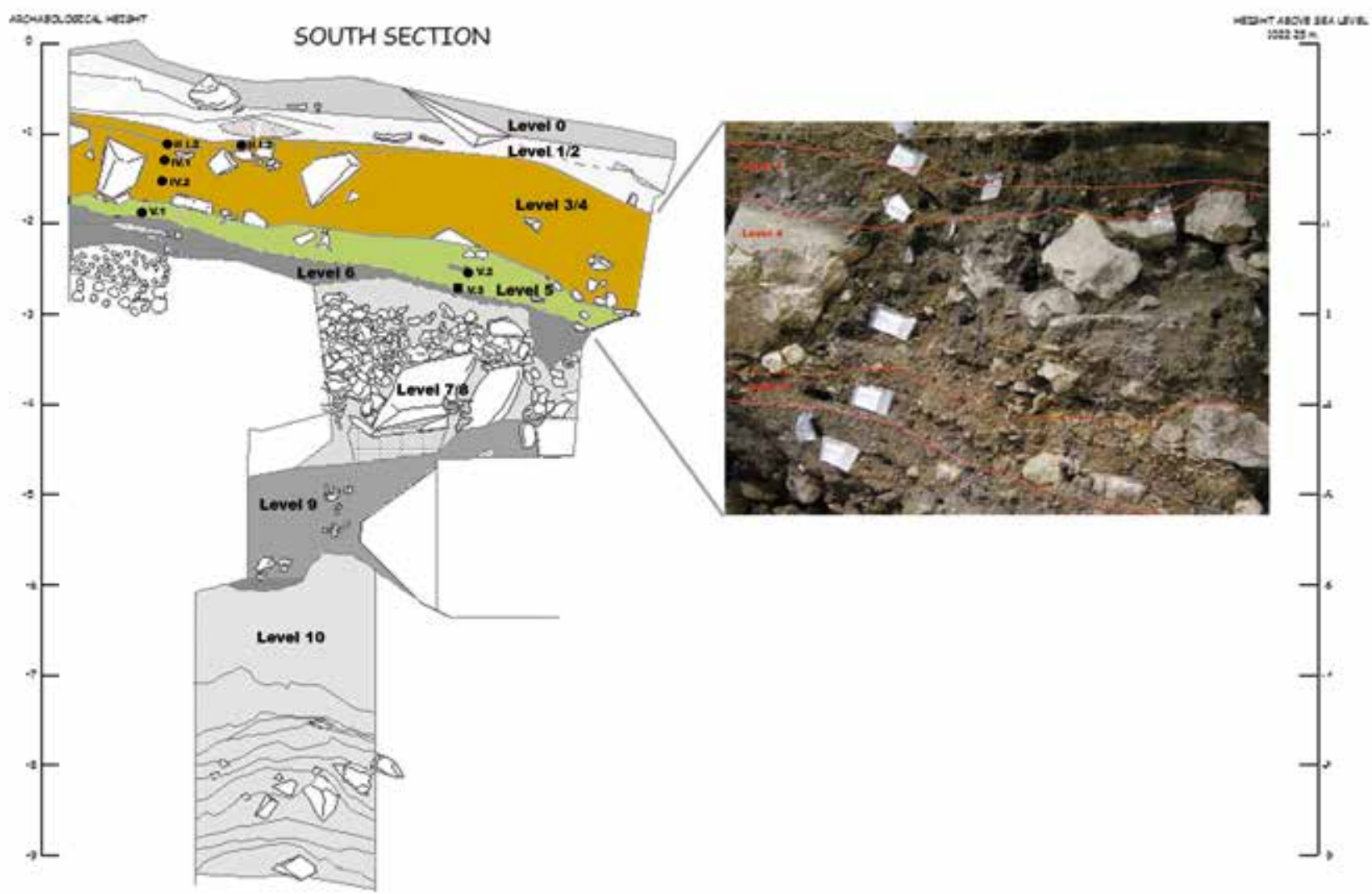

Fig. 2. Secuencia arqueoestratigráfica del perfil sur de El Portalón de Cueva Mayor con los niveles que corresponden a las ocupaciones del Bronce (antiguo y medio) coloreados. / Archaeostratigraphic sequence of the Southern section of El Portalón de Cueva Mayor. Colored levels correspond to the Early and Middle Bronze Age levels.

continuado de la cavidad, siendo relativamente intensa la ocupación durante la Edad de Bronce, exhumada por Apellániz en las áreas de excavación abiertas, y que ha proporcionado una abundantísima colección material donde destaca, por su volumen, la cerámica.

A día de hoy la Edad del Bronce es un periodo cultural bien representado en la cavidad, tanto por la potencia de los niveles, como por el volumen de su inventario material y la batería de referencias radiocarbónicas. Aunque ya se han publicado otros materiales del Bronce (ALDAY et al., 2011; ALDAY et al., 2015; PÉREZ-ROMERO et al., 2015a, algunos análisis de la fauna (GALINDO-PELLICENA et al., 2015) y de paleogenética (SVERRISDÓTTI et al., GÜNTHER et al., 2015), son pocos los trabajos publicados sobre el registro cerámico (CLARK et al., 1979; MÍNGUEZ, 2005) y falta un análisis detallado y de conjunto de los materiales cerámicos a lo largo de todo el período.

El objetivo de este trabajo es precisamente realizar un análisis detallado de la alfarería de la edad del Bronce de El Portalón, época que, desde nuestra perspectiva, está representada por las etapas iniciales (Nivel 5) y medias (Niveles 4 y 3) (Figura 2). Hay que señalar sin embargo que Mínguez (2005) realizó un estudio sobre un conjunto cerámico de El Portalón atribuido por Ape-
Ilániz al Bronce final. Esos materiales son revisados en este trabajo y atribuidos, mayoritariamente, al Bronce medio en base a nuevas dataciones radiocarbónicas realizadas posteriormente al estudio de Mínguez y la correlación que hemos realizado entre los lechos arqueológicos definidos por J.M. Apéllaniz y los nuevos niveles estratigráficos definidos por el EIA (ver PÉREZ-ROMERO et al., 2015).

\section{2.- MATERIAL Y MÉTODOS}

La descripción sedimentológica y las dataciones de todos los niveles de El Portalón puede encontrarse en CARRETERO et al. (2008), PÉREZ-ROMERO et al., (2015). Aquí incluimos solamente las dataciones pertenecientes a los 3 niveles de la Edad del Bronce (Tabla 1, Figura 3) y a continuación una sucinta descripción sedimentológica de los mismos:

Bronce Medio, Nivel 3.- Conjunto de limos-arcillosos arenosos de color gris oscuro, de $16 \mathrm{~cm}$ de espesor medio, con abundancia de materia orgánica, carbones y elementos de la cultura material (cerámicas, objetos óseos y líticos, fauna...). La serie de valores radiométricos fijan este nivel hacia el último tercio del IV milenio BP. (Tabla 1; Figura 3). 


\begin{tabular}{|c|c|c|c|c|}
\hline No LABOR. & FECHA B.P. & MATERIAL & NIVEL & CALIBRACIÓN $2 \sigma$ \\
\hline Beta-395880 & $3300 \pm 30$ & Hueso (Castor fiber) & N3 & $3610-3450$ \\
\hline Beta-153360 & $3330 \pm 70$ & Sedimento & N3 & $3730-3410$ \\
\hline Beta-253407 & $3370 \pm 40$ & Diente (Equus sp) & $\mathrm{N} 3 / 4$ & $3720-3520$ \\
\hline Beta-201761 & $3330 \pm 60$ & Carbón & $\mathrm{N} 3 / 4$ & $3710-3430$ \\
\hline Beta-253407 & $3370 \pm 40$ & Diente (Equus sp) & $\mathrm{N} 3 / 4$ & $3720-3520$ \\
\hline Ua-32851 & $3355 \pm 40$ & Hueso (Bos, $2^{\mathrm{a}}$ falange) & $\mathrm{N} 3 / 4$ & $3710-3470$ \\
\hline Beta-209454 & $3380 \pm 40$ & Carbón & $\mathrm{N} 3 / 4$ & $3730-3530$ \\
\hline Ua-22026 & $3385 \pm 35$ & Diente (Bos taurus T3) & N4 & $3740-3540$ \\
\hline Ua-22027 & $3415 \pm 45$ & Diente (Bos primigenius) & N4 & $3800-3560$ \\
\hline Beta-253413 & $3460 \pm 40$ & Diente (Equus sp) & N4 & $3880-3600$ \\
\hline Ua-22028 & $3485 \pm 45$ & Diente (Bos taurus T1) & N4 & $3890-3650$ \\
\hline Beta-212188 & $3490 \pm 40$ & Carbón & N4 & $3890-3650$ \\
\hline Beta-200992 & $3500 \pm 40$ & Diente (Equus sp) & N4 & $3880-3680$ \\
\hline Beta-201758 & $3520 \pm 40$ & Carbón & N4 & 3920-3680 \\
\hline Ua-32852 & $3535 \pm 40$ & Diente (Bos, molar sup.) & N3 & $3950-3670$ \\
\hline Beta-184840 & $3560 \pm 40$ & Carbón & $\mathrm{N} 3 / 4$ & $3990-3710$ \\
\hline Beta-222336 & $3560 \pm 50$ & Hueso & N4 & $4010-3690$ \\
\hline Beta-200993 & $3600 \pm 40$ & Diente (Equus sp) & N4 & $4020-3820$ \\
\hline Beta-153362 & $3630 \pm 40$ & Carbón & N5 & $4080-3840$ \\
\hline Beta-269493 & $3630 \pm 40$ & Hueso & N5 & $4080-3840$ \\
\hline Beta-224079 & $3670 \pm 40$ & Hueso & N5 & $4150-3870$ \\
\hline Beta-253409 & $3690 \pm 40$ & Diente (Equus sp) & N5 & $4150-3910$ \\
\hline Beta-200994 & $3630 \pm 40$ & Diente (Equus sp) & N5, L caballos & $4080-3840$ \\
\hline Ua-32245 & $3495 \pm 45$ & Diente (Equus sp) & N5, L caballos & $3900-3660$ \\
\hline Ua-32854 & $3635 \pm 40$ & Hueso (Bos $1^{\text {a }}$ falange) & N3 & $4110-3830$ \\
\hline Beta-200991 & $3640 \pm 40$ & Diente (Equus sp) & $\mathrm{N} 4 / 5$ & $4120-3840$ \\
\hline Beta-209453 & $3650 \pm 40$ & Sedimento & N5, L caballos & $4130-3850$ \\
\hline Beta-153361 & $3680 \pm 40$ & Carbón & N4 & $4140-3900$ \\
\hline Beta-253409 & $3690 \pm 40$ & Diente (Equus sp) & N5 & $4150-3910$ \\
\hline Beta-253412 & $3690 \pm 40$ & Diente (Equus sp) & N5/6 & $4150-3910$ \\
\hline Beta-253410 & $3700 \pm 40$ & Diente (Equus sp) & N5/6 & $4170-3930$ \\
\hline Beta-184843 & $3700 \pm 70$ & Carbón & N5/6 & $4250-3850$ \\
\hline Beta-253411 & $3710 \pm 40$ & Diente (Equus sp) & N5 & $4290-4010$ \\
\hline Beta-184839 & $3740 \pm 40$ & Carbón & $\mathrm{N} 5 / 6$ & $4230-3950$ \\
\hline Beta-224080 & $3760 \pm 40$ & Hueso & N5 & $4290-3970$ \\
\hline Beta-224454 & $3760 \pm 50$ & Diente (Equus sp) & N5 & $4310-3950$ \\
\hline Beta-184838 & $3760 \pm 40$ & Carbón & N5/6 & $4290-3970$ \\
\hline
\end{tabular}

Tabla 1: Dataciones radiométricas en BP y Cal BP obtenidas en los niveles arqueológicos de la Edad del Bronce de El Portalón./Radiocarbon dates in BP and Cal BP of the Bronze Age archaeological levels from El Portalón.

Bronce Medio, Nivel 4.- Paquete homogéneo de sedimentos limos-arcillosos a arenosos de entre 70 y $150 \mathrm{~cm}$. de espesor, incrementando su potencia hacia el interior de la cavidad (hacia el N). Destaca en este nivel, la presencia de numerosos clastos y grandes bloques calizos procedentes de los desplomes de las paredes y el techo, así como su riqueza en materia or- gánica y carbones. Una decena de fechas de C14 nos sitúa en el segundo tercio del IV milenio BP (Tabla 1; Figura 3).

Bronce Antiguo, Nivel 5.- Con una potencia de 35 $\mathrm{cm}$ es una capa de limo-arcillosa arenosa de tonos grisáceos (10YR 6/1) con abundantes carbones y cenizas en la base. Arqueológicamente abundan las cerámicas 


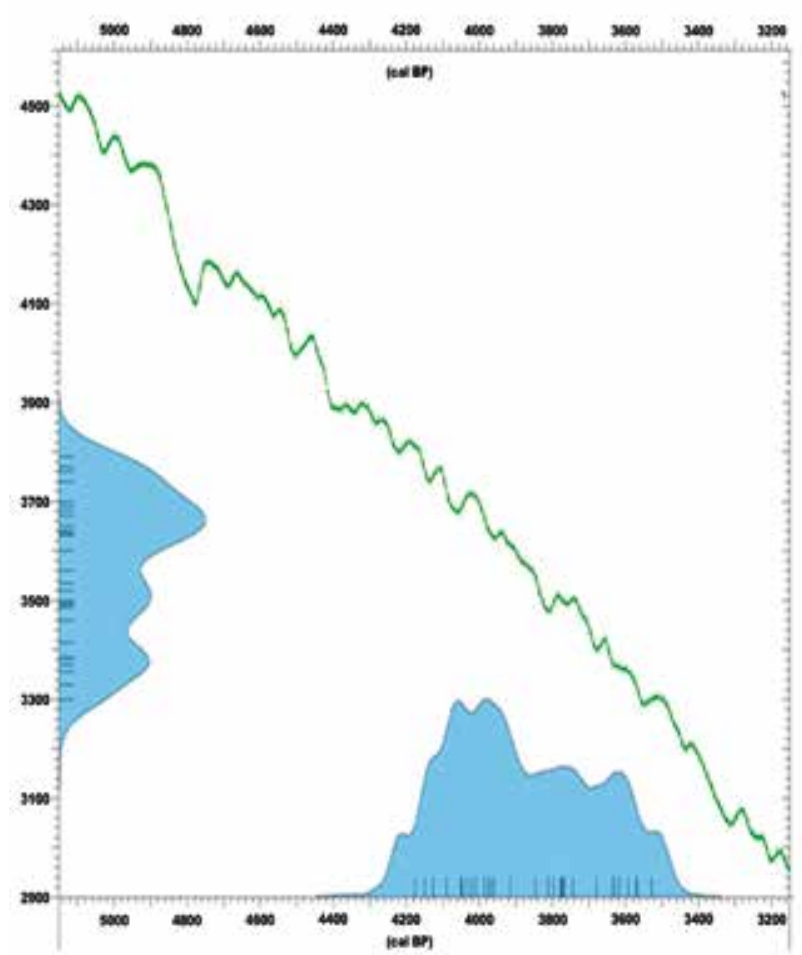

Fig. 3. Distribución cronológica de las edades radiométricas obtenidas en los niveles de la Edad del Bronce de El Portalón de Cueva Mayor (Tabla I). Edades calibradas mediante Calpal. / Chronological distribution of the radiocarbon dates (CALPAL calibration curve) of the Bronze Age levels from El Portalón de Cueva Mayor (Table 1).

y, en menor medida, la industria ósea, lítica y los restos de fauna. Una quincena de valores radiocronológicos señalan el segundo cuarto del IV milenio como el momento de su formación (Tabla 1; Figura 3).

Se incluyen en este trabajo los materiales cerámicos del Bronce recuperados en las excavaciones de $\mathrm{G}$. Clarck (1972) y Juan M. Apellániz (1973-1983) depositados en el Museo Provincial de Burgos. No se incluyen sin embargo en este estudio los materiales arqueológicos extraídos por el ElA entre los años 2000 y 2006 debido a que provienen, de forma mayoritaria, del vaciado de un antiguo pozo clandestino realizado en medio del yacimiento. Durante esos años se realizaron labores de desescombro y excavación de los sedimentos de relleno que colmataban ese pozo y de los materiales caídos de las paredes de las intervenciones previas a la nuestra durante los 16 años de inactividad. No hemos podido conocer la autoría del pozo pero dadas las dimensiones que presenta, pensamos que se trata de una cata minera y en todo caso, de una intervención en la que tuvieron que trabajar obreros con buenos medios técnicos y humanos para la evacuación de toneladas de tierra y rocas y no simples aficionados a la arqueología (Figura 4).

Hemos podido determinar que el conjunto de los materiales arqueológicos recuperados por Clark y Apellániz en los niveles de la Edad del Bronce ronda los 35.000 elementos. Si descontamos aquellos fragmen-

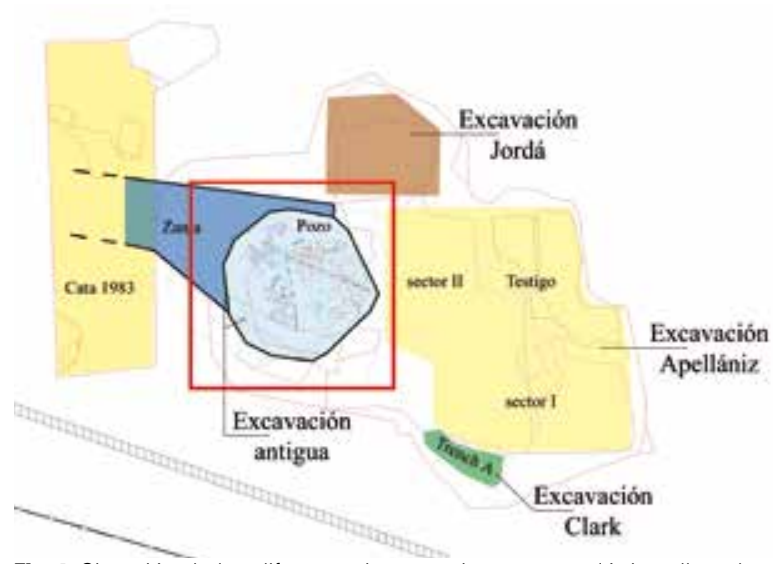

Fig. 4. Situación de las diferentes intervenciones arqueológicas llevadas a cabo en El Portalón de Cueva Mayor. El espacio situado dentro del recuadrado rojo corresponde a la zona de intervención del EIA entre los años 2000-2006. / Situation of the different archaeological excavations carried out in El Portalón de Cueva Mayor. The EIA's intervention areas between 2000 and 2006 indicated with the red squares.

tos de pequeño tamaño, informes, muy deteriorados o con ciertas incertidumbres estratigráficas el número final queda reducido a 24.127 de los cuales, la gran mayoría, corresponde a fragmentos cerámicos (22.055, el $91,4 \%)$, seguido de restos de fauna con $1.769(7,3 \%)$ (GALINDO-PELLICENA, 2014; GALINDO-PELLICENA et al., 2015), quedando muy por detrás la industria lítica, 216 (0,9\%), la ósea 70 (0,3 \%) (ALDAY et al., 2011; PÉREZ-ROMERO et al., 2015) y metálica, 17 (0,08\%) (Figura 5).

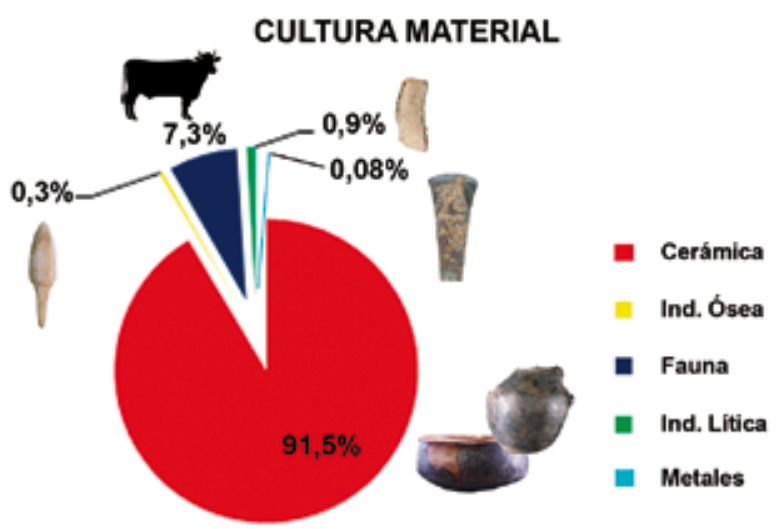

Fig. 5. Representación porcentual de los distintos tipos de materiales arqueológicos recuperados en los niveles de la Edad del Bronce en El Portalón. / Proportion of the different types of archaeological materials recovered in the Bronze Age levels from El Portalón.

La alta fragmentación de la cerámica recuperada limita el reconocimiento detallado de sus caracteres morfológicos, no obstante, a partir del remontaje de algunos fragmentos, de las piezas más grandes y de los elementos más singulares, hemos obtenido una visión razonable de la vajilla del asentamiento. Para ello, 
de entre los 22.055 fragmentos, hemos seleccionado aquellos que aportan algún tipo de información: la totalidad de los elementos decorados, los bordes, galbos de mayor tamaño, los elementos de suspensión y los fondos de las formas lisas.

Como hemos mencionado más arriba, dentro del conjunto distinguimos dos grandes series cerámicas que evaluamos independientemente: una del Bronce antiguo (N-5) y una del Bronce medio (N-4, N-3). Cada uno de los fragmentos ha sido tratado individualmente, comparando sus caracteres y cuantas representaciones gráficas se han considerado necesarias dentro de una gran base de datos.

Para los procesos de catalogación formal se ha recurrido a los trabajos de LLANOS Y VEGAS, 1974; JIMENO et al., 1988; DELIBES et al., 1990; RODRÍGUEZ MARCOS, 2008; FERNÁNDEZ MARTÍN, 2012; FERNÁNDEZ MORENO, 2013.

Para la descripción de las características tecnológicas y cualitativas nos ha parecido suficiente la observación directa y con lupa binocular, al tratarse de una colección normalizada en los patrones propios de la época, que no exigen atenciones específicas. En la diferenciación de las inclusiones y la clasificación de la manufactura en grupos nos hemos basado en los criterios establecidos por Cubas (2013).

Para cada fase cultural el estudio se inicia con un catálogo de formas-tipos, continuará con la descripción de los elementos más característicos (bordes, bases, sistemas de aprehensión) finalizando con la evaluación de las técnicas y motivos decorativos. De forma breve se hará alusión a las características técnicas, las propiedades de las pastas y a distintos aspectos relacionados con la producción.

\section{3.- RESULTADOS}

\subsection{La Cerámica del Bronce antiguo/pleno}

El inventario está compuesto por 11.249 elementos, mayoritariamente galbos (10.350, 92\%), seguidos de bordes $(610,5,4 \%)$, fondos $(278,2,5 \%)$, elementos de suspensión $(44,0,4 \%)$ y, a nivel anecdótico fichas (5), fusayolas (2) y 1 fragmento de tapa. Solo se han podido remontar nueve formas completas o casi completas, lo que da idea de la gran fragmentación de la colección.

Las cerámicas han podido ser clasificadas en una tabla tipológica que refleja la suma de los distintos arquetipos que ha sido posible diferenciar. Atendiendo a los perfiles generales de las piezas distinguimos seis formas (de A a F) incluyendo como tal los coladores o encellas, que más que un modelo formal es un útil con una función muy definida (FERNÁNDEZ MORENO, 2013). Para cada forma clasificaremos diversos tipos $(1,2,3 \ldots)$ que a su vez pueden organizar variantes (estas se designarán con letras minúsculas).

\subsubsection{Formas y Tipos}

Forma A.-Cuencos. En esta forma presenta un perfil abierto y volumen relacionado con la esfera, estando en su borde el máximo diámetro de la pieza. Se ha concretado la presencia de 152 (41,6\%), de los cuales 28 presentaban algún tipo de decoración. Dentro de esta forma se han diferenciado 4 tipos con sus distintas variantes (Figura 6, A).

Tipo A1.-. Su perfil que se acerca a la media esfera $(92,60,5 \%)$. Son elementos muy comunes ya sean de pequeño o de mediano tamaño (su diámetro puede oscilar entre los 70 y los 170 mm) (Figura 6, A1). En algunos casos sus bordes tienden a abrirse ligeramente (A1a); en otros casos adoptan tienden a formas más abiertas, aproximándose a las cónicas (A1b) y finalmente aparecen cuencos con las características de los anteriores pero que presentan mayor altura (A1c).

Tipo A2.- Caracterizados por superar la media esfera $(36,23,5 \%)$ y por tanto cerrarse hacia la boca, siendo sus bordes ligeramente entrantes (Figura 6, A2). Los tamaños que presentan son más reducidos que los anteriores, con medidas que van desde los $85 \mathrm{~mm}$ a los 120 mm (A2a). En algunos casos llevan en la panza asas de lengüeta (A2b).

Tipo A3.- De paredes verticales $(21,13,9 \%)$ que originan formas tendentes a lo cilíndrico. Todos los que aparecen en el inventario de El Portalón carecen del tercio inferior, no siendo posible su adecuada reconstrucción (Figura 6, A3)

Tipo A4.- La característica más destacable de este tipo es lo reducido de su tamaño por lo que a menudo se les denomina vasitos o cubiletes e interpretados como piezas de entretenimiento o juguetes. Su diámetro no supera los $50 \mathrm{~mm}$. De este tipo se han recuperado $3(2,6 \%)$ (Figura 6, A4).

Forma B.- Formas de perfil en "S". Se trata de ollas o contenedores caracterizados principalmente por su perfil sinuoso, cuya parte superior (boca y cuello) es siempre una forma cóncava que deriva en formas cilíndricas o hiperbólicas, mientras que el cuerpo suele ser esférico u ovoide (RODRÍGUEZ MARCOS, 2008). Es la segunda forma en cuanto al número de elementos (113, $31 \%$ ), oscilando sus dimensiones entre los 400 a los 80 $\mathrm{mm}$. Dentro de esta se han podido establece tres tipos con sus respectivas variantes (Figura 6, B):

Tipo B1.- Su abstracción formal es de tipo ovoide, con cuello estrangulado, muy corto y un borde exvasado. Son piezas de tamaño grande ya que la mayoría de ellas presentan o sobrepasan los $200 \mathrm{~mm}$. Es el más habitual de esta forma $(57,50,5 \%)$ (Figura 6, B1).

B1a.- De cuello alto, muy corto y amplio Su diámetro máximo se encuentra en la panza.

B1b.- Esta se ha individualizado por la habitual presencia de impresiones en el labio.

B1c.- Representa un caso único de contorno sinuoso abierto y cuyo borde sobrepasa los $190 \mathrm{~mm}$. Este 
borde está rematado por un labio redondeado con impresiones digitales.

Tipo B2.- Presentan, además de un cuello marcado, un acusado cambio de dirección en la parte superior del galbo y un borde diferenciado recto o muy poco vuelto, alcanzando diámetros en la boca de más de 300 mm (Figura 6, B2). Han sido 37 los restos recuperados (34,5\%). Rara vez aparecen decorados (B2a) y cuando lo están se resumen a digitaciones en el borde (B2b)

Tipo B3.- Olla de borde vuelto y cuello muy poco marcado. Es el tipo menos numeroso (17, 15\%) (Figura 6, B3a y b)

Forma C.- Vasos Carenados. 48 vasijas de perfil anguloso, (13,2\%). Su mayor diámetro (entre los 358 y los $100 \mathrm{~mm}$ ) coincide con la carena Dentro de esta forma cabe diferenciar tres tipos con diversas variantes (Figura 6, C):

Tipo C1.- Con carena en el tercio superior, por lo que presenta un volumen superior poco desarrollado rematado un borde muy saliente. Los tamaños de este tipo son muy diversos, (entre 180 y $250 \mathrm{~mm}$ ) Entre sus 16 fragmentos $(14,6 \%)$ la mayor o menor angulosidad del borde en relación con la carena determina las variantes (Figura 6, C1):

C1a.- Incluye a los recipientes más abiertos su perfil superior es cóncavo, mientras que el inferior es convexo, presentándose en una gran variedad de tamaños y con decoración tanto incisa como impresa sobre la carena (Figura 6, C1a).

C1b.-Este una forma más cerrada que la anterior y con notable diferencia entre el cuello y la panza. Se ha reconstruido una gran cazuela, que supera los $350 \mathrm{~mm}$, de borde curvado y ligeramente abierto, cuerpo inferior troncocónico con paredes ligeramente convexas (Figura 6, C1b).

Tipo C2.-En estos tipos la carena se posiciona hacia la mitad de los recipientes, presentando un perfil inferior convexo y un cuerpo superior troncocónico. Es la forma que presenta menos número de fragmentos ( 7 , 14,6\%) y variantes (Figura 6, C2).

C2a.- Presenta un borde recto con labio redondeado y cuello muy corto y marcado. El perfil tiende a la verticalidad (Figura 6, C2a).

C2b.- Su descripción se basa en un recipiente casi completo de borde recto ligeramente abierto, labio redondeado, perfil superior cóncavo e inferior tiende a convexo y base plana. Presenta esquemas decorativos muy barrocos en el exterior con juego de incisiones e impresiones. El fondo también se decora.

Hemos de señalar que este vaso carenado, por la calidad de su pasta y por sus motivos ornamentales, es único en el contexto del Bronce antiguo de El Portalón e incluso a nivel del territorio más inmediato. Los paralelos más cercanos se encuentran en yacimientos situados en el valle del Ebro y Cataluña (MAYA y PETIT, 1986), lo que nos estaría hablando de relaciones con puntos relativamente alejados Además, hay que mencionar que este vaso apareció en un contexto junto a numerosos restos de caballo en comparación con momentos anteriores y posteriores. El perfil de edad de los animales y el patrón de fracturación y marcas de los huesos demuestra un intenso consumo de animales jóvenes (GALINDO-PELLICENA et allí, 2015). Apellániz quiso interpretar este conjunto, y esta singular pieza, como parte de un ritual realizado en la Cueva durante el Bronce Antiguo, pero las evidencias de las que disponemos hasta ahora no son ni mucho menos concluyentes(Figura 6, C2b).

Tipo C3.- Caracterizado por la posición baja de sus carenas (Figura 6, C3). Es la forma más común en el Bronce antiguo, presentando tanto paredes en disposición casi vertical sin cuello y borde recto (C3a), como formas más cóncavas y el borde exvasado (C3b) mostrando, mayoritariamente, labios apuntados (25, 33,3\%).

Forma D.- Vasos globulares. De morfología de tendencia elíptica cuyo máximo diámetro está situado en la parte media/superior. Hemos reconocido 31 vasijas (8,5\%), de las cuales 11 presentan alguna decoración. Dentro de esta forma hemos podido establecer tres tipos (Figura 6, D):

Tipo D1.- Vasijas con cuerpo de paredes de tendencia globular y borde sencillo entrante, sin cuello, rematando la parte superior del hombro de la panza directamente en un labio redondeado (17 restos) (Fig. 6, D1). Son recipientes de tamaño pequeño/mediado ya que los diámetros de su zona más ancha oscilan entre los 120 a los 200 mm. Las diferencias dentro de este tipo residen en el distinto índice de inflexión del borde hacia el interior del recipiente más marcada en algunos casos (D1a) o menos perceptible (D1b)

Tipo D2.- Recipientes de forma globular, cuello incipiente poco marcado y borde levantado con disposición vertical ligeramente abierto (Figura 6, D2). Se trata de la forma menos representada ya que tan solo contamos con la presencia de 4 fragmentos (D2a) y sus diámetros (en los dos casos que presentamos) no superen los 130 $\mathrm{mm}$. En un caso presentan impresiones digitales en el labio (D2b).

Tipo D3.- Se formula este tipo para dar cabida a formas globulares con cuerpos esferoides que presentan una curvatura muy pronunciada por un cambio pronunciado en la dirección del cuello que marca un borde muy diferenciado. Presentan decoración impresa en el borde (Figura 6, D3).

Forma E.- Encaja aquí el morfotipo conocido como colador o encella: para el Bronce antiguo contamos con 20 fragmentos (5,5\%). Las perforaciones afectan a los tramos superiores de las paredes. Su uso está relacionado con la transformación de productos lácteos (Figura 6, E).

Forma F.- Este grupo lo forman los restos de un gran vaso troncocónico de perfil y paredes rectas y un diámetro de boca en torno a los 400 mm (0,3\%) (Figura 6, F). 


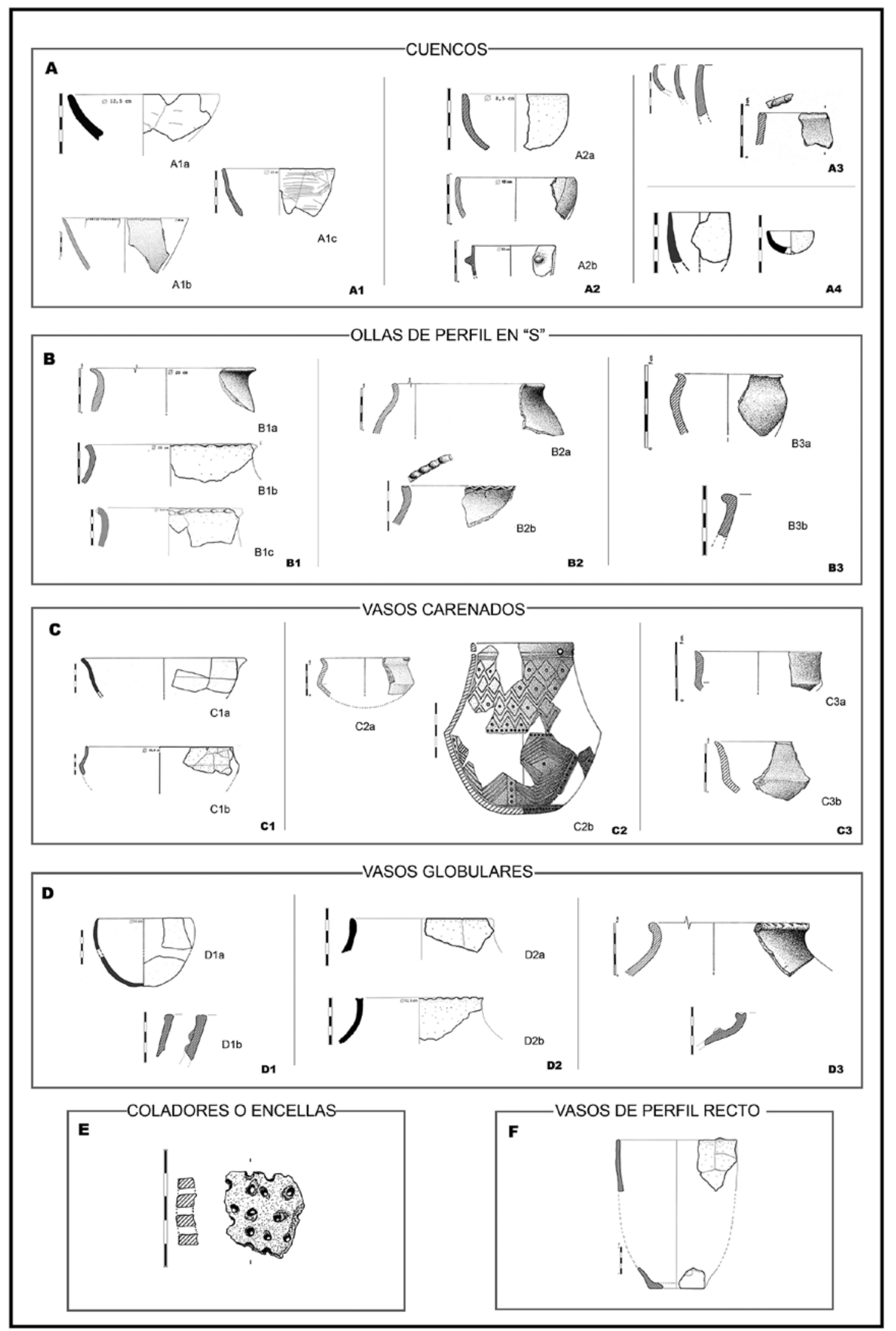

Fig. 6. Formas cerámicas (lisas y decoradas) pertenecientes al Bronce antiguo del yacimiento de El Portalón de Cueva Mayor (Sierra de Atapuerca). / Types of Early Bronze Age pottery (plain and decorated) from El Portalón. 


\subsubsection{Otros aspectos formales}

\subsubsection{Bordes}

Los 628 bordes incluidos en el estudio suponen un $5,8 \%$ de los fragmentos cerámicos adscritos al Bronce antiguo y se distribuyen en 5 categorías. Dominan los abiertos $(35,6 \%)$, seguido de los rectos $(17,5 \%)$ y a larga distancia de los vueltos $(4,1 \%)$, los exvasdos $(1,8 \%)$, y los cerrados $(1,8 \%)$ No obstante, los indeterminados alcanzan el $39,8 \%$ de la colección. Están decorados el $56,8 \%$ de los bordes, con claro predominio de lo impreso. (Figura 6).

\subsubsection{Galbos}

Presentan el grueso de la colección (10.029, 94,8\%) y ponen de manifiesto la presencia tanto de paredes curvas como rectas, presumiéndose la presencia de recipientes de alta capacidad, para el almacenaje, y de dimensiones más propias para actividades domésticas y de cocina. De este conjunto tan solo presentan decoración 201 fragmentos.

\subsubsection{Fondos/bases}

Entre las bases recuperadas es escasa variedad tipológica. El número de piezas seleccionadas es de 278 $(2,5 \%)$, pero en la mayoría de los casos no se han podi- do vincular formas de vasijas con tipos de fondos. Hemos agrupado las variantes en tres grandes conjuntos (de F1 a F3), con sus respectivas variantes (Figura 7).

F1. Planos: Se trata del grupo mayoritario ya que suponen el 97,1\% (Figura 7, F1). Dos ejemplares conservan improntas de cestería y 9 improntas vegetales (Figura 7, F1). La conexión con la pared puede hacerse de forma muy marcada (F1a); en una suave curva al elevarse el centro de la base (F1b) o en ángulo abierto (F1c).

F2.- Bases cóncavas caracterizadas por un pequeño umbo (2,5\%) (Figura 7, F2).

F3.- Se ha recuperado un solo fragmento con pie indicado $(0,4 \%)$ (Figura 7, F3).

\subsubsection{Elementos de sujeción}

Contabilizamos 44 elementos $(0,4 \%)$ del total de piezas recuperadas observándose una relativa variedad (Figura 7). Los más habituales son las lengüetas/orejetas (36,4\%) (Figura 7, A1), seguidos de mamelones (34,1\%) (Figura 7, A2) ya sean troncocónicos o cilíndricos. Se han recuperado 8 fragmentos de asas (18,2\%, (Figura 7, B) diferenciando entre las de forma de cinta (4 de sección plana (B1a), 2 de sección circular (B1b) y 2 tubulares) y el arranque de otras 2. Por último, 5 casos $(11,4 \%)$ presentan perforaciones como sistema de sujeción (Figura 7, C).

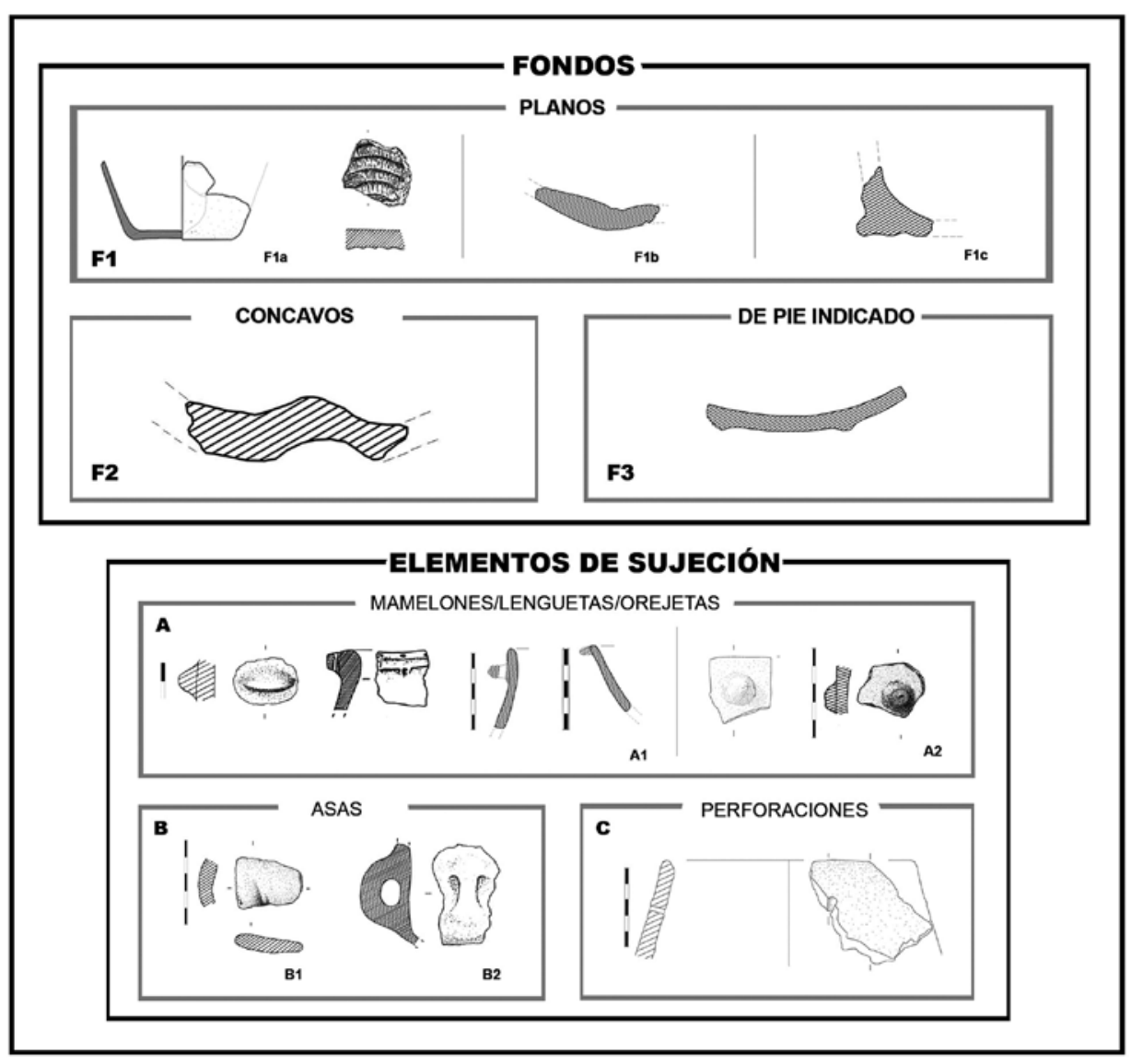

Fig. 7. Diferentes tipos de fondos y elementos de sujeción pertenecientes a los niveles del Bronce antiguo. / Different classes of bottoms and fixing elements of the pottery from the Early Bronze Age levels of El Portalón. 


\subsubsection{Técnicas decorativas}

Las técnicas decorativas son uno de los criterios habituales para la clasificación de las colecciones cerámicas y los yacimientos de los que proceden, y, en consecuencia, de los grupos humanos que las fabricaron (ROJO et al., 2013).

Desde el punto de vista ornamental el conjunto es bastante sencillo y homogéneo, ello a pesar de contar con un buen número de evidencias (434 casos, 4,2 \% del inventario). Debido al alto grado de fragmentación rara vez se puede asociar técnicas y sintaxis decorativa con formas/tipos, limitando la capacidad de nuestra colección. Por técnicas diferenciamos entre: impresas, incisas, plásticas, mixtas, esgrafiadas y boquique.

A.- Decoración impresa.- La técnica decorativa más común con 218 fragmentos $(50,2 \%)$, normalmente se presenta en disposición discontinua (Figura 8, A). Es frecuente que en los bordes aparezcan decoraciones impresas a bases de (Figura 8, A1): digitaciones (A1a), digito-ungulaciones ( $\mathrm{A} 1 \mathrm{~b}) \mathrm{o}$, en menor medida, ungulaciones (A1C).

Con menor frecuencia este tipo de decoraciones se disponen sobre cuellos y panzas (Figura 8, A2), generalmente alineadas o en combinaciones simples paralelas, realizadas con dedos/uñas (A2a), o con punzones (romos, apuntados o de terminaciones rectangulares) (A2b y A2c).

B.-Decoración plástica. Es la segunda técnica más representada $(98,22,6 \%)$, ubicándose indistintamente bajo el borde, en el cuello o en el cuerpo (Figura 8, B). Dentro de este tipo reconocemos:

- Aplicaciones lisas (33) (Figura 8, B1) a la manera de cordones simples (B1a) (10), botones cónicos o pitones (B1b) (14) y apliques circulares (2) (B1c). A estos hay que añadir 7 casos indeterminados. Somos conscientes de la posible doble función, de decoración y sujeción, que estos elementos pudieron desempeñar.

- Aplicaciones compuestas (65) (Figura 8, B2) sean cordones sencillos, normalmente horizontales con impresiones digitales (B2a) (42), digito-ungulaciones (B2b) (5), impresiones de punta roma (B2c) (4) y aplicaciones circulares digitadas (B2d) (4). En algunos casos se combinan varios cordones (Figura 8, B3), en paralelo (B3a) formando ondas (B3b) y siempre decorados con digitaciones o digito-ungulaciones.

Sin ser estrictamente aplicaciones, y con una funcionalidad más de agarre que ornamental, la colección se completa con acabados toscos, rugosos, conseguidos mediante pellizcos con los dedos.

C.- Decoración incisa. Está presente en 55 fragmentos (12,7\%) Figura 8, C). Los temas más característicos son las líneas incisa simples (33), múltiples o paralelas (Fig. 8, C1) destacando las variedades en retícula (4) con diferentes orientaciones y grados de perfección (Figura 8, C2), espigas (4) (Figura 8, C3), y líneas zigzag
(2) (Figura 8, C4). En 5 galbos las incisiones organizan cenefas con triángulos rellenos de finos trazos incisos (Figura 8, C5).

D.-Decoración mixtas. No es una técnica propiamente dicha, sino que reúnen los fragmentos que combinan algunas de las técnica anteriores, lo que ocurre en un $11,3 \%$ de los materiales cerámicos decorados, siendo la más utilizada la impresión +incisión (Fig.8, D1) que en algún caso se rellena de pasta blanca (Figura 8, D2).

E.- Decoración esgrafiada.- Son 12 fragmentos los que presentan este tipo de decoración (2,8\%) (Figura 8, E) que asociarían esta técnica a formas de cuello alto y panza globular, desarrollando temas de dientes de lobo (Figura 8, E1), zigzag aislados (Figura 8, E2) o en combinación con espigas (Figura 8, E3).

F.- Boquique.- Se nos presenta un solo caso con esta técnica decorativa $(0,2 \%)$ (Figura $8, F)$.

G.- Cordado Aislamos el único caso del conjunto de impresiones por su singularidad $(0,2 \%$ ) (Figura 8, G).

H.- Este apartado incluye casos específicos como son la presencia de 9 ejemplares con decoración peinada (Figura 8, H1), de acanaladuras en 2 fragmentos (Figura $8, \mathrm{H} 2$ ) y de un recipiente de pasta fina, con inclusiones cuarcíticas pequeñas e irregulares, acabado bruñido y cocción reductora con decoración incisa en toda la superficie del vaso y como bandeado series de rombos con punción central (incluso el fondo del recipiente aparece con esta decoración) que reflejan influencias de grupos orientales (Arbolí) (MAYA y PETIT, 1986) (Figura 8, H3).

\subsubsection{Tecnología}

\subsubsection{Tratamiento de las superficies}

En principio, salvando alguna excepción, las superficies de la mayoría de los recipientes se trataron mediante diversas técnicas: alisados $65,7 \%$, bruñidos $31,2 \%$, barbotinas $1,7 \%$, siendo testimonial el espatulado y el cepillado. No siempre se ha podido determinar el tratamiento de las superficies debido a la precipitación de concreciones o deterioro de las paredes, incluso a su desaparición en relación a procesos tafonómicos y/o de uso.

Hemos observado algunas claras asociaciones entre forma/tipo y algunos acabados. Así en las vasijas carenadas y en los cuencos dominan las paredes bruñidas, mientras que en las vasijas grandes (¿almacenaje?) y en otras que asumimos su uso para la cocina predominan los alisados.

\subsubsection{Cocciones}

Para el análisis de las cocciones seguimos, principalmente, los criterios de García y Calvo (2006) en el que se combinan diferentes variables de estudio, aunque modificado algunas de ellas para adaptarlas a nuestro caso. 

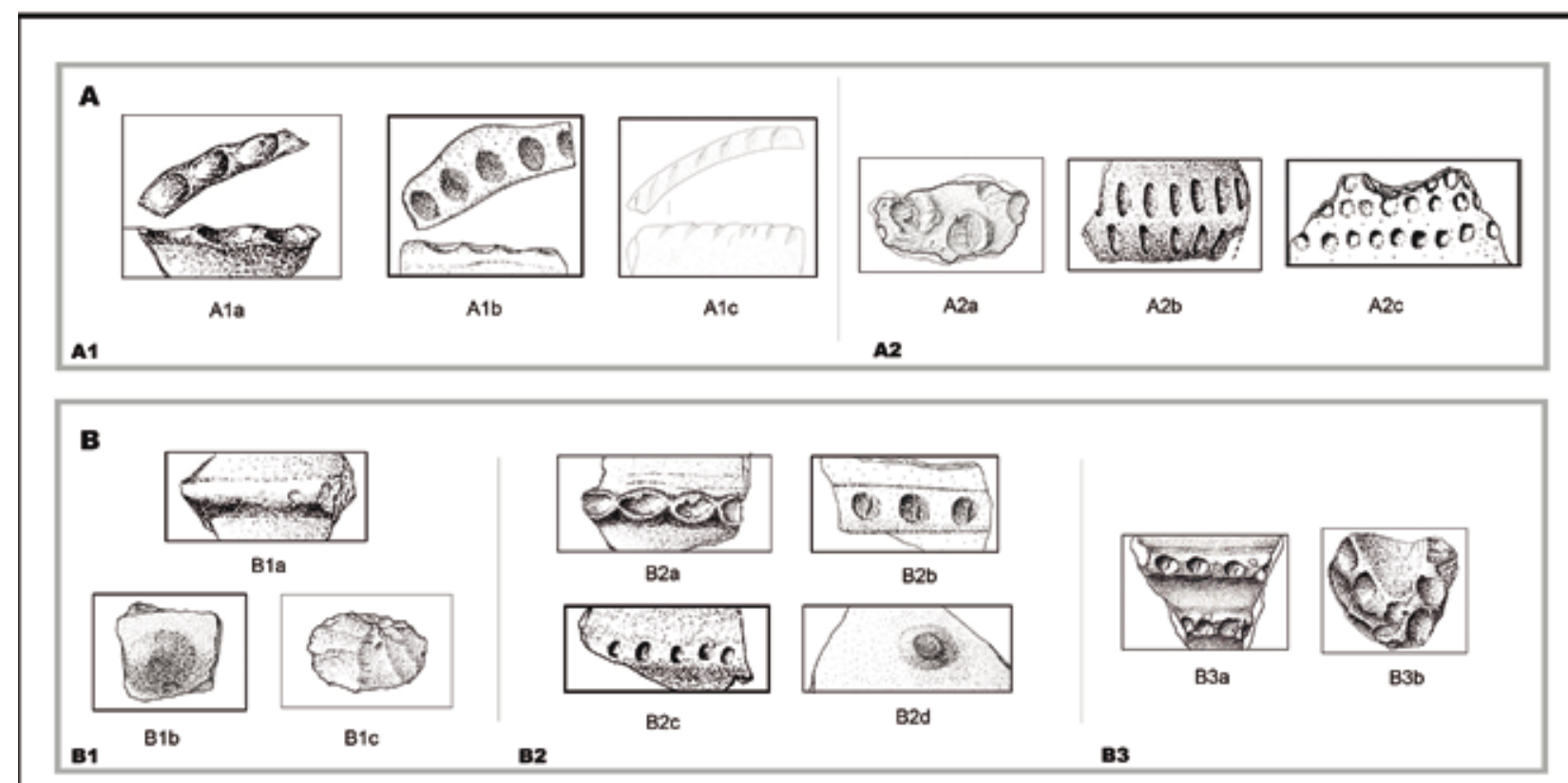

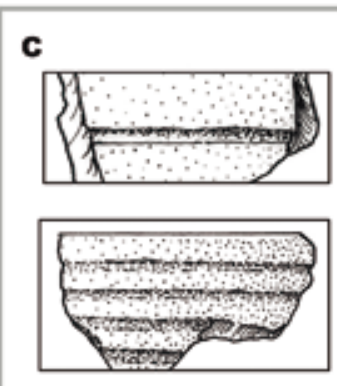

c1

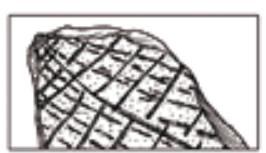

C2

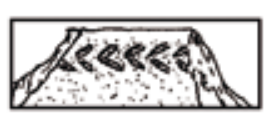

c3
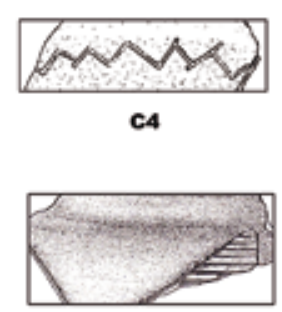

C5
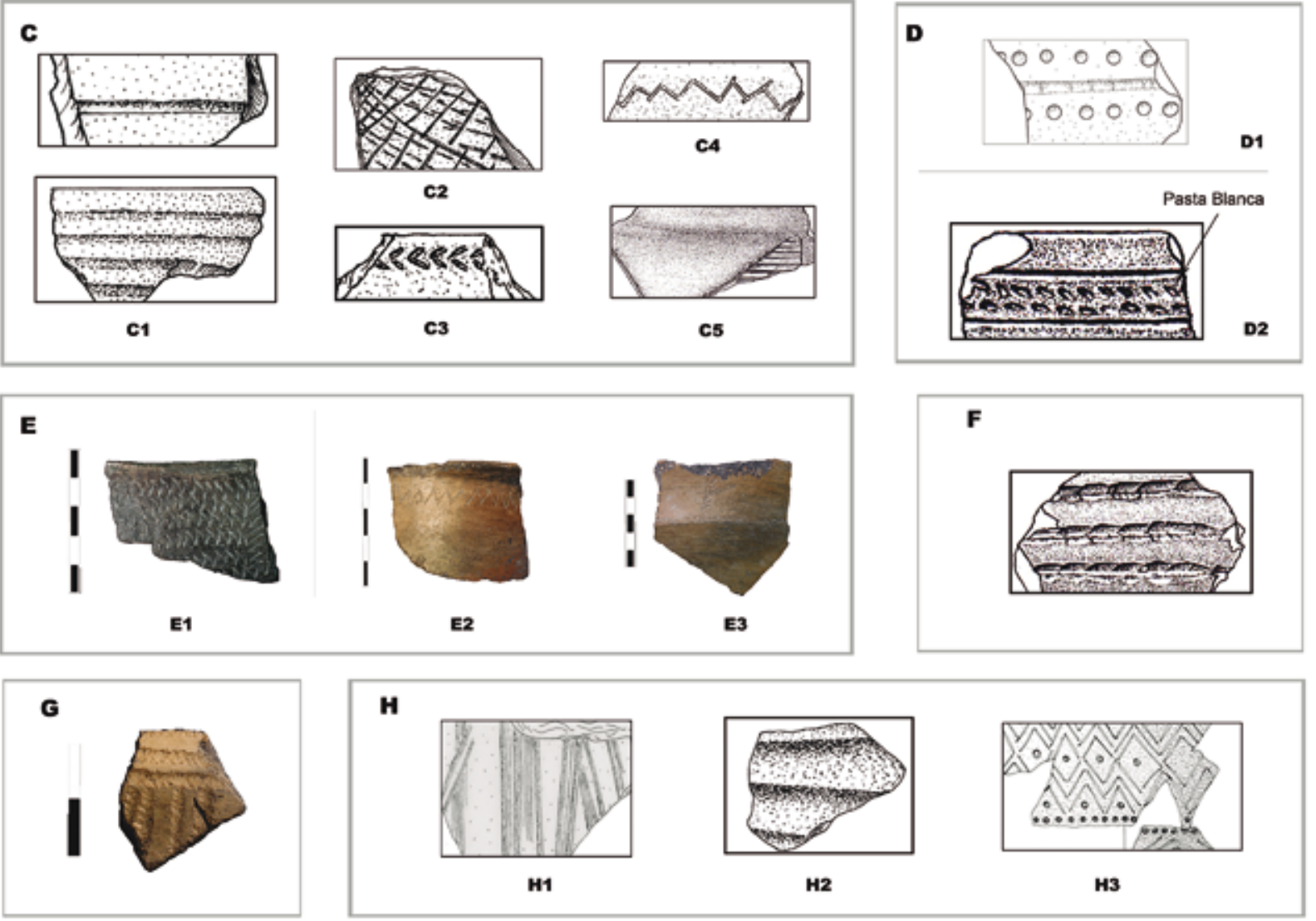

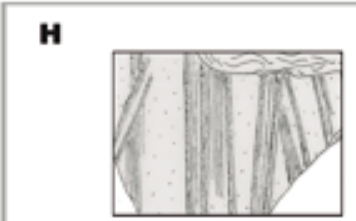

H1

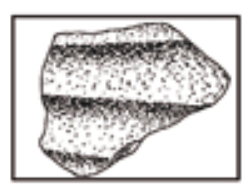

$\mathbf{H 2}$

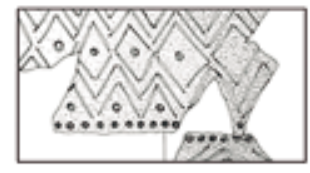

H3

Fig. 8. Principales motivos identificados en la decoración cerámica del Bronce antiguo del yacimiento de El Portalón. / Main decorative motives identified in the Early Bronze Age pottery from El Portalón.

Señalaremos que, en primer lugar, dado el importante grado de fragmentación que presenta la colección, no hemos tenido en cuenta aquellas piezas cuyas superficies, por su pequeño tamaño, no pueden considerarse diagnósticas en relación con este tema. Sin estos casos la cocción reductora es mayoritaria $(78,5 \%)$ 
seguida de la reductora con postcocción oxidante $(8,7 \%)$ que confieren a las superficies exteriores tonalidades que van del marrón anaranjado al gris oscuro y negro. Los fragmentos de cocción irregular suponen un $12,7 \%$, mientras que las oxidantes son anecdóticas (si en realidad no representan a cerámicas de cocción irregular).

Los casos estudiados muestran tal variabilidad de tonalidades en secciones y superficies que pone de manifiesto una falta de estabilidad durante el proceso de cocción. Así, los colores y tonalidades más representados son los tonos oscuros, negros y grisáceos, si bien la presencia de coloraciones rojizas es algo habitual en las paredes. No obstante, aquellos casos de coloraciones uniformes, grises y negras, generalmente asociados a las vajillas más cuidadas como vasos carenados y cuencos bruñidos, nos hacen pensar en una estrategia de cocción diferencial según los intereses o usos que se vayan a dar a las producciones.

\subsubsection{Grosor medio de las cerámicas}

Asumiendo que en toda artesanía alfarera a mano la variabilidad en el grosor de los elementos, es dependiente tanto de los objetivos buscados en el proceso técnico, como de la habilidad del ceramista, tomamos este índice con mucha precaución. Pero, en general, se aprecia una importante homogeneidad, donde el 92\% de los casos estaría dentro del tramo comprendido entre los 5-10 mm.

\subsection{5.- Otros elementos cerámicos}

Sirve este apartado para reunir otros elementos cerámicos de funcionalidad distinta a las cerámicas vasculares: fusayolas (2) y fichas (5). Las primeras indicarían la manipulación de fibras vegetales o animales por parte de los grupos asentados en el Portalón, revelando la plurifuncionalidad del lugar (JOVER Y LÓPEZ, 2013) (Figura 9, A). Como "ficha" clasificamos una pieza discoidal, recordando que se relaciona su uso con el juego o como elementos de contabilidad (PICAZO, 1993) (Figura 9, B).
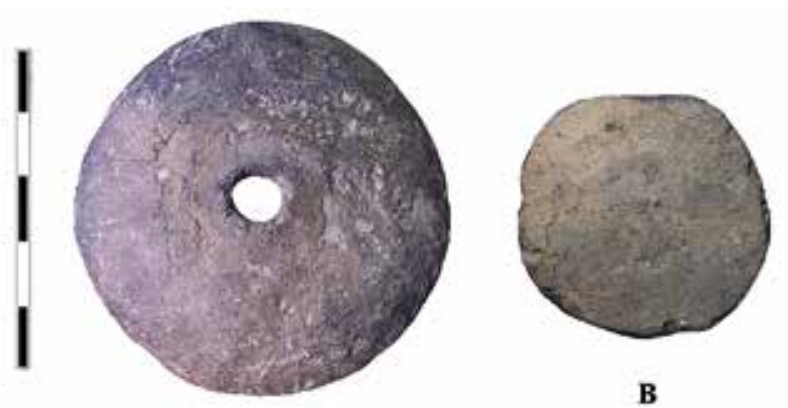

A

Fig. 9. A) Fusayola con morfología circular, sección frontal de tendencia ovoide y perforación central. B) Ficha. / A) Circular Fusayola with ovoid frontal section and a central perforation. B) Counter.

\subsection{La Cerámica del Bronce medio}

Su inventario lo componen 9929 fragmentos (provenientes tanto de las excavaciones de Apellaniz como Clark), y de los cuales 9020 son galbos (90,8\%), 663 bordes $(6,7 \%), 210$ fondos $(2,1 \%), 27$ elementos de suspensión (0,3\%), 4 fragmentos de queseras, 4 fichas y 1 fragmento de tapa. A pesar de esta importante cantidad de materiales solo se ha podido reconstruir 4 formas al completo.

\subsection{1.- Formas y Tipos}

También aquí el pequeño tamaño de los fragmentos impide una buena lectura de la mayor parte de los elementos de la base de datos. Así la catalogación y jerarquización de las formas se alcanza a partir de 238 fragmentos que, por sus características tanto de tamaño como por pertenecer a una parte significativa a la hora de determinar de qué tipo de forma se trata, permiten caracterizar el repertorio cerámico adscrito al Bronce medio.

A nivel formal el Bronce medio presenta las mismas categorías que el periodo anterior.

Forma A.- Cuencos. Presentan las mismas características que los asignados al Bronce antiguo. Se han recuperado 86 fragmentos $(36,1 \%)$, reconocidos como partes de estos recipientes, las variantes propias del periodo anterior, pero con una mayor cantidad de fragmentos decorados (54) (Figura 10, A):

Tipo A1.- 47 fragmentos $(54,6 \%)$ de cuencos de casquetes semiesféricos de pequeño/mediano tamaño cuyos diámetros oscilan entre los 70 y los 160 mm (Figura 10, A1). Dentro de este tipo podemos diferenciar entre: cuencos cuyos bordes son ligeramente abiertos (A1a); cuencos que tienden a alejarse un poco de las formas semiesféricas, aproximándose a las cónicas (A1b) y , los que por su altura, superan la media esfera y suelen ser más hondos (A1C).

Tipo A2.- En 25 casos (29,05\%) los cuencos son altos y tienden a cerrarse en la boca ya que sus bordes son ligeramente entrante (Figura 10, A2). En algunos casos estos cuencos llevan para su sujeción asas de lengüeta o mamelones próximos al borde (A2b).

Tipo A3.- Cuencos con paredes verticales hay 12 (14\%) (Figura 10, A3). Tan solo se ha recuperado un fragmento con borde decorado con impresiones (ungulaciones).

Tipo A4.- Recipientes con volumen troncocónico de tamaño pequeño/medio ya que el diámetro de su boca no supera los $150 \mathrm{~mm}$. (Figura 10, A4)

Tipo A5.- De este tipo se han recogido 2 galbos $(2,4 \%)$ de muy pequeñas dimensione ya que sus diámetro no superan los $70 \mathrm{~mm}$. Son los denominados vasitos o cubiletes (Figura 10, A5). 
Forma B.- Formas de perfil en "S". En este apartado incluimos todos aquellos perfiles sinuosos (ollas/ cazuelas) observados en 71 fragmentos $(29,8 \%)$. Aparecen frecuentemente decorados ya que en 62 está presente algún tipo de decoración. Atendiendo a su perfil y proporciones se detecta la presencia de tres tipos distintos de variantes (Figura 10, B).

Tipo B1.- Se han recuperado 45 fragmentos de perfil acusadamente esférico y cuellos poco marcados, cortos y con bordes diferenciado normalmente abiertos y redondeados (Figura 10, B1) oscilando los diámetros de su boca entre los $120 \mathrm{~mm}$ hasta los $300 \mathrm{~mm}$ (B1a). Las decoraciones parecen fundamentalmente en el borde (digitaciones, ungulaciones y en menor medida con útil). Se ha recuperado una sola pieza con decoración acanalada en la panza y digitaciones en el borde (B1b).

Tipo B2.- Son 14 los restos que presentan cuellos marcados y estrangulados por un acusado cambio de dirección en la parte superior del galbo y bordes diferenciados vueltos con labio normalmente plano (Figura 10, B2). Se trata de recipientes de tamaño mediano grande, llegando a superar, en algún caso los 400 mm de diámetro. En su doble variante se muestran tanto sin decoración, las más numerosas (B2a), como decoradas, fundamentalmente con impresiones en el borde (B3b).

Tipo B3.- Está variante compuesta por 10 fragmentos está definida por los recipientes que presentan, además de un cuello poco marcado un borde diferenciado recto o muy poco vuelto (Figura 10, B3). La mayor parte de los recipientes carecen de decoración (B3a) aunque algunos ejemplares muestran digitalizaciones en el labio y en un caso, además, sobre un cordón situado en el cuello (B3b).

Tipo B4.- No reconocido en el Bronce antiguo recoge una gran cazuela decorada con impresiones unguladas en el borde y aplique de un pequeño pitón (Figura 10, B4).

Forma C.- Los vasos carenados están bien representados (52 fragmentos, $21 \%$ ), variando tipos por la disposición de las carenas (altas, medias y bajas) (Figura $10, C)$.

Tipo C1.- De carena alta en los que apenas de desarrolla el cuerpo superior (Figura 10, C1). Dentro de este tipo se ha podido diferenciar entre los que presentan formas más abiertas y rectas con bordes muy salientes sin decoración (C1a) y los decorados (C1b), pudiendo variar sus tamaños entre los 80 a loa $150 \mathrm{~mm}$ y un solo caso con características son distintas ya que la forma es más cerrada (C1c). Corresponde al tipo mejor representado con 32 fragmentos.

Tipo C2.-la posición media de las carenes está presente en 15 casos (Figura 10, C2). Este tipo diferencia un perfil inferior convexo otro superior troncocónico que remata en un borde más o menos saliente. La mayor (C2a) o menor (C2b) apertura del borde en, así como el diámetro de la carena, determina las variantes.

Tipo C3.- Con carena baja situada en el tercio inferior de la pieza siendo, mayoritariamente, el cuerpo inferior semiesférico y el superior troncocónico (Figura 10, C3). En esta forma se han podido detectar dos variantes: de boca cerrada (C3a) o abierta con labio apuntado (C3b).Es el tipo menos común con 5 fragmentos.

Forma D.- El número de fragmentos mínimo perteneciente a las formas globulares es de 13 (5,5\%) y están mayoritariamente decorados (8). La muestra tiende a simplificarse en lo relativo a las variantes (Figura 10, D):

Tipo D1.- De perfiles sencillos y continuos, sin cuello y con borde entrante. El índice de inflexión que adopta el borde hacia el interior del recipiente es bastante marcado (Figura 10, D1).

Tipo D2.- Globular con borde entrante diferenciado del cuerpo (Figura 10, D2) sin (D2a) o con decoración (en un caso mixta impresa y con aplicada con impresiones sobre el cordón (D2b). Dentro de este tipo se ha recuperado una pequeña jarrita completa con asas (D2c).

Forma E.- La presencia de16 fragmentos de encellas $(6,7 \%)$ es significativa a tenor de su presumible función (Figura 10, E).

\subsection{2.- Otros aspectos formales}

\subsubsection{Bordes}

Los 633 bordes incluidos en el estudio, suponen un $6,7 \%$ del inventario cerámico adscrito al Bronce medio. Están presentes las 5 categorías habituales. El mejor representado son los abiertos $(28,4 \%)$, seguidos de los rectos $(10,4 \%)$, cerrado $(2,8 \%)$, vueltos $(2,1 \%)$ y exvasados $(0,8 \%)$. Los indeterminados suman el $55,5 \%$ por causa de su fragmentación y las pequeñas dimensiones (Figura 10).

Los bordes lisos $(63,7 \%)$ superan a los decorados, entre los que predomina la técnica impresa.

\subsubsection{Galbos}

Suman $9.046(90,8 \%)$, reflejando la presencia de formas simples, curvas o rectas $(98,1 \%)$ junto $d$ a las carenadas. (1,9\%). De este conjunto tan solo presentan decoración 195 fragmentos.

\subsubsection{Fondos/Bases}

Se reconocen claramente como bases es de 210 $(2,1 \%)$ sin poder relacionar sus cuatro variantes ( $F 1$ a F4) con forma singularizadas (Figura 11).

F1. Planos, que son el grupo mayoritario $(95,7 \%)$, entre los que 9 que presentan improntas de cestería y 3 improntas vegetales (Figura 11, F1). El contacto con la panza es, según casos en ángulo recto marcado (F1a) o mediante un suave estrangulamiento (F1b). 


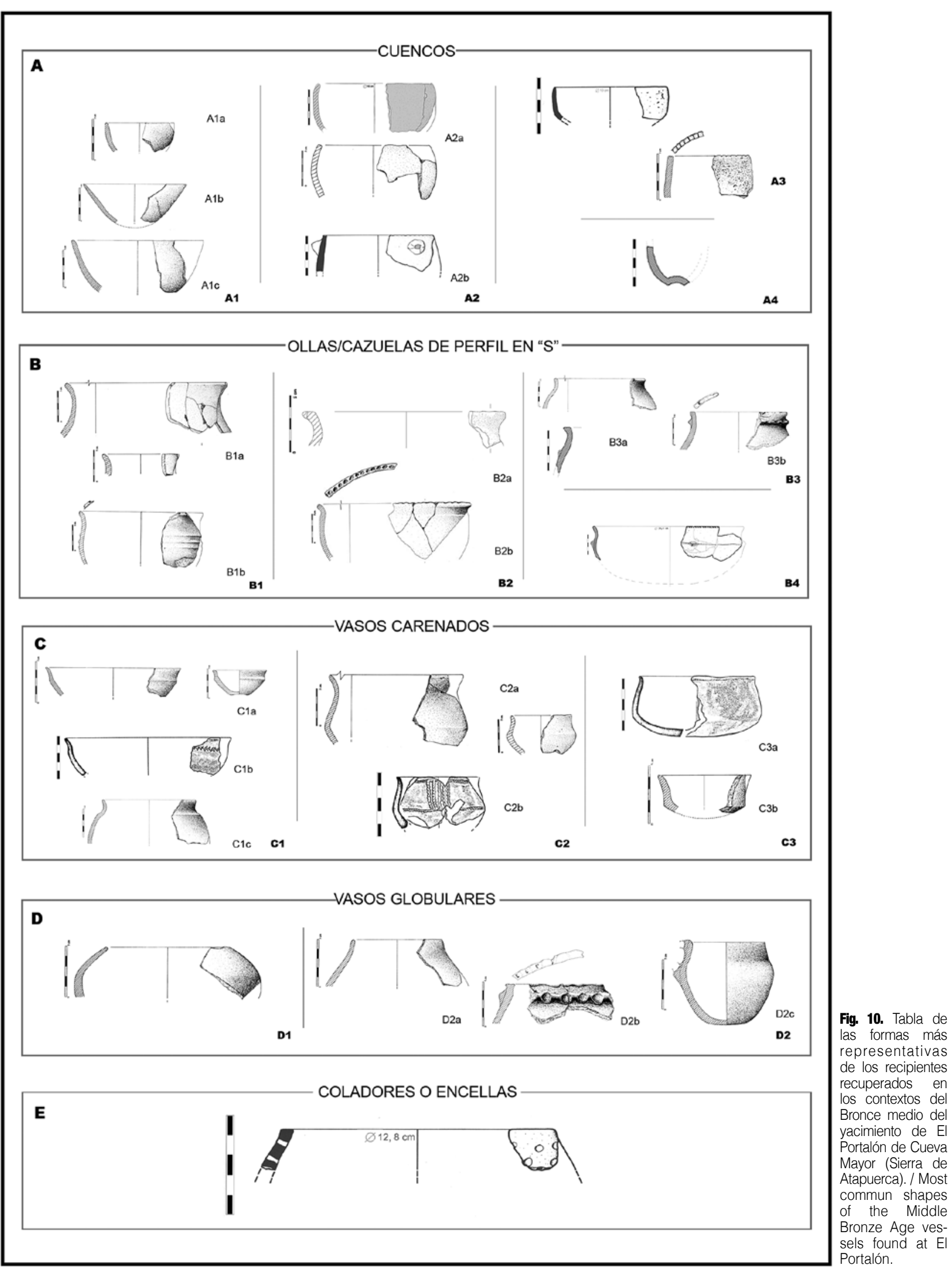




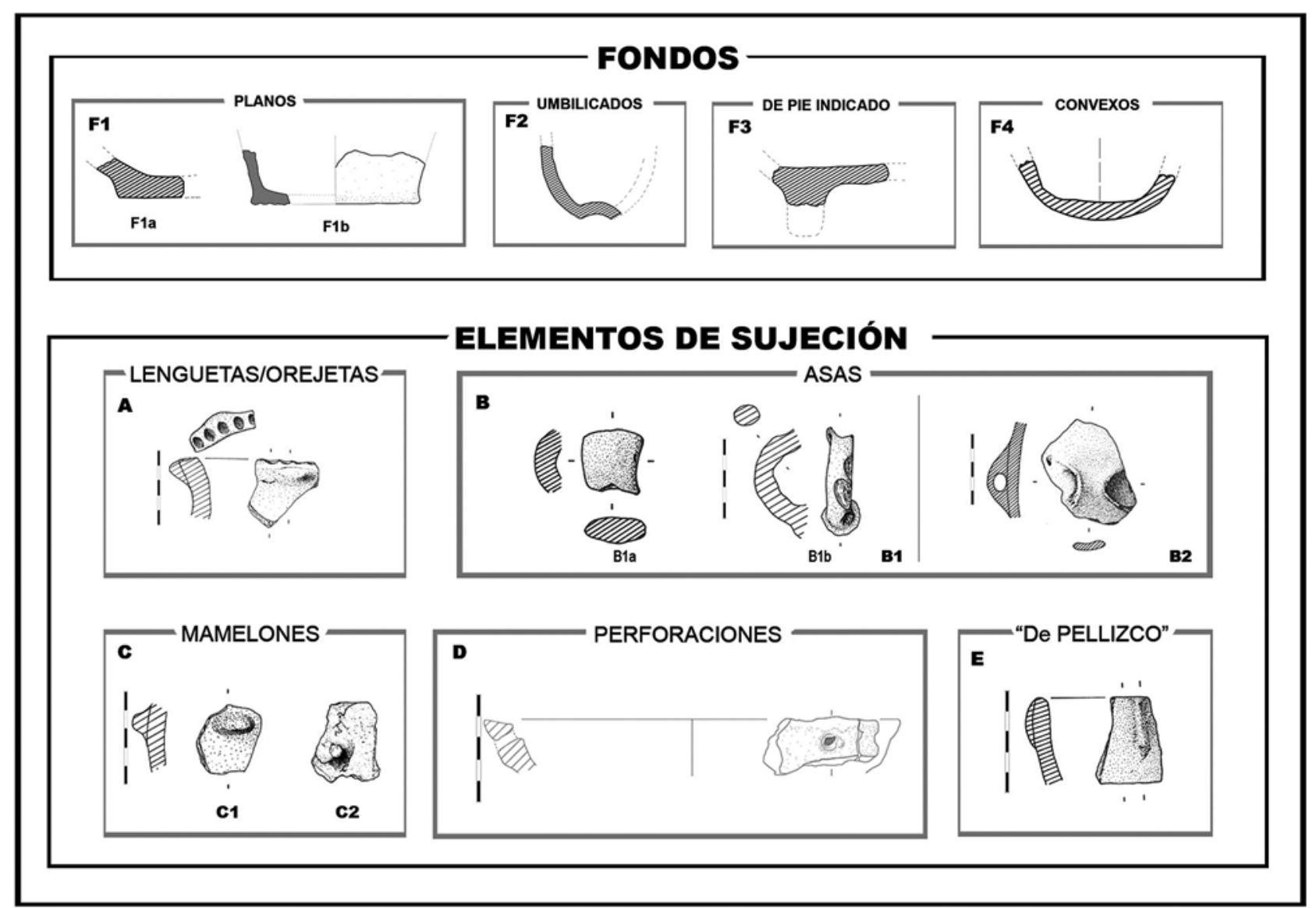

Fig. 11. Fondos y elementos de sujeción registrados en los niveles del Bronce medio en el yacimiento de El Portalón (Sierra de Atapuerca). / Different classes of bottoms and fixing elements of the pottery from the Middle Bronze Age levels of El Portalón.

F2.- Cóncavas/umbilicadas que suponen el 2,9\% del conjunto (Figura 11, F2).

F3.- Con pie indicado: 2 fragmentos (1\%) (Figura 11, F3).

F4.- Convexo.- Un fragmento de fondo convexo $(0,5 \%)$ (Figura 11, F4).

De gran interés es el hallazgo de un considerable número de fondos con impronta de cestería. Las muestras de esta técnica son bastante excepcionales en la bibliografía ya que tan solo aparecen documentadas, en el Bronce medio en el yacimiento de El Castillo.

\subsubsection{Elementos de sujeción}

Son escasos los sistemas de prensión reconocidos en esta unidad, 27 (0,3\%), y limitadas sus variantes.

Los más habituales son las lengüetas/orejetas ( 9 , $33,3 \%$ ) (Figura 11, A), seguidas de las asas de cinta (8, 29,6\%,) (Figura 11, B1): (6 de sección plana (B1a), 1 de sección circular (B1b) y 1 como "de puente" (Figura 11, B2). Los mamelones (Figura 11, C) suponen un 22,2\%, sean simples prominentes $(\mathrm{C} 1)$ o con impresión digital (C2). Fragmentos con perforaciones como sistema de sujeción son $3(11,1 \%$ ) (Figura 11, D) y hay también un asa "de pellizco" (3,7\%) (Figura 11, E).

\subsection{3.-Decoraciones}

El número de muestras que presentan algún tipo de ornamentación es de 333, (2,9\% del total) pero como es norma habitual en la colección, por el estado general que presenta no es posible vincular técnicas/temas con volúmenes tipificados. La figura 12 sintetiza los temas más significativos y las ligeras variantes.

A.-Decoración impresa.- Son103 fragmentos $(30,9 \%)$ los que presentan decoración impresa (Figura 13, A) aplicada preferentemente sobre bordes y labios (Figura 12, A1), apareciendo de forma más frecuente las digitalizaciones (59) (A1a), las ungulaciones (A1b) y digito-ungulaciones (A1C) (35). Menos frecuentes son las impresiones realizadas con instrumento, incluyendo como tal el uso de una ruedecilla (Figura 12, A2). La presencia de este tipo de motivos es menor en paredes y cuellos, aunque tenemos algún ejemplo de su presencia (Figura 12, A3).

B.- Decoración Plástica.- Numéricamente a la par que las anteriores, 102 fragmentos (30,6\%) (Figura 12, B).entre los que hemos podido diferenciar:

B1.- Simples (51) (Figura 12, B1): cordones (B1a), circulares (B1b) y pastillas (B1c), con claro predominio de los primeros. 

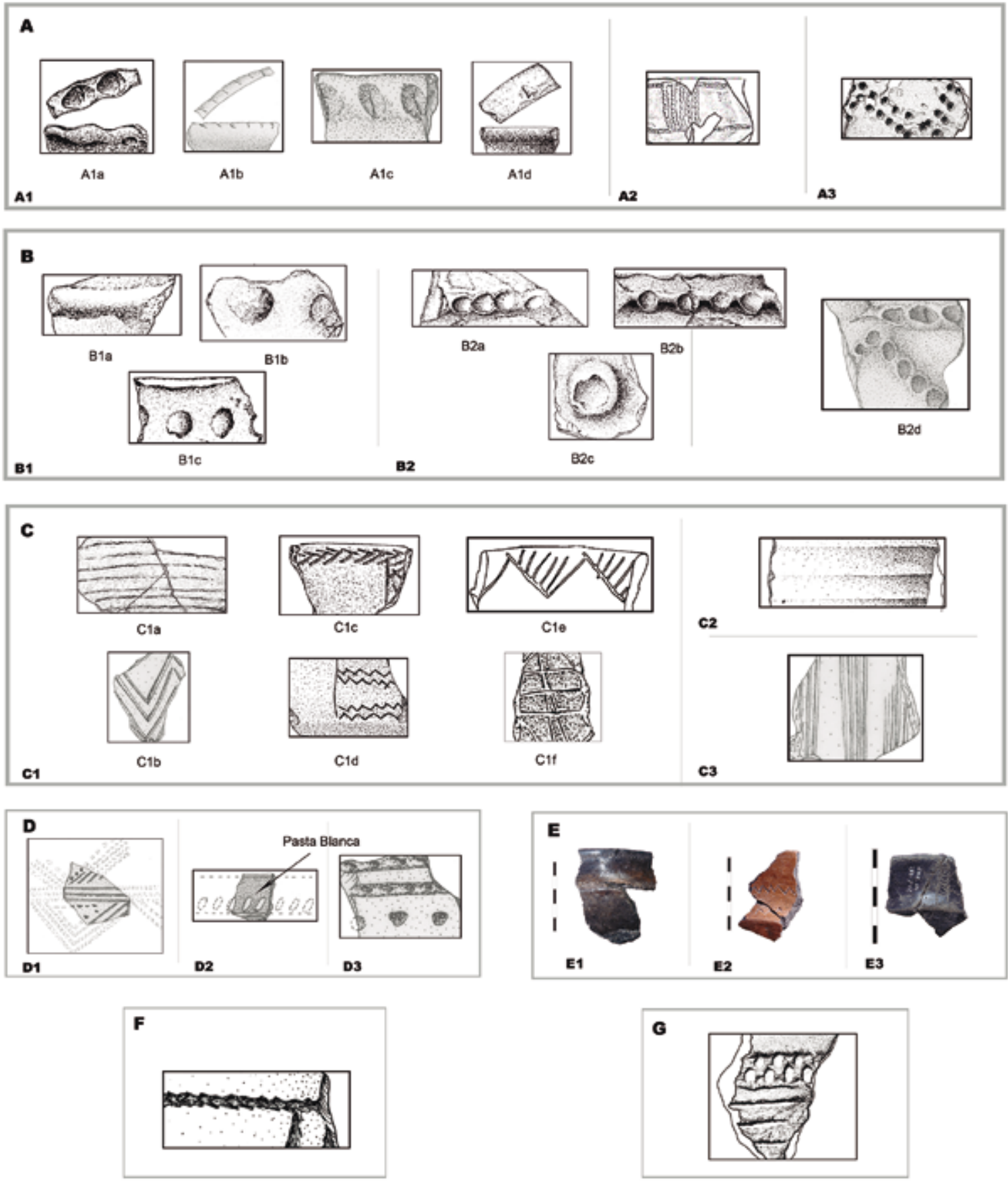

Fig. 12. Tabla tipológica de los motivos decorativos de la cerámica de los niveles del Bronce medio en el yacimiento de El Portalón de Cueva Mayor (Sierra de Atapuerca). / Main decorative motives identified in the Middle Bronze Age pottery from El Portalón.

B2.- Decoradas (51) (Figura 12, B2): cordones digitados (B2a), ungulados o decorados con impresiones realizadas con útil $(\mathrm{B} 2 \mathrm{~b})$, circulares con digitaciones (B2c) y, en menos casos, cordones múltiples digitado o digito-ungulados (B2d). Como en el caso anterior existe un predominio de los cordones, en este caso digitados.
C.-Decoración Incisa.- El conjunto de este tipo decorativo representa un 16,2\% (54) (Figura 12, C), que configuran diseños geométricos, siendo las más numerosas las líneas (27) (Figura 12, C1), simples o paralelas, horizontales o verticales $(\mathrm{C} 1 \mathrm{a})$ o formando líneas quebradas (C1b), frente a composiciones motivos 
en espiga (9) (C1c), líneas formando zigzag (5) (C1d), composiciones triangulares (5) (C1e), y un reticulado (C1f). Entre las incisiones también encontramos algunos fragmentos con acanaladuras (10) (Figura 12, C2) e incisiones realizadas a peine (3) (Figura 12, C3).

D.- Decoración mixta. En 38 fragmentos $(11,4 \%)$ la combinación de técnicas desarrolla sintaxis más elaboradas (Figura 12, D): la fórmula más asidua aúna incisión-impresión (21) (Figura 12, D1); que ocasionalmente se rellena con pasta blanca (2) (Fig. 12, D2), boquique- impresión (5) (Figura 12, D3), boquique-incisión (1) y varios motivos, algunos de ellos indeterminados (9)

E.- Decoración esgrafiada.- 28 fragmentos $(8,4 \%)$ (Fig. 12, E) presentan motivos en forma de: dientes de lobo (15) (Figura 12, E1), zigzag (11) (Fig. 12, E2) o la combinación de varios (2) (Figura 12, E3).

Por último señalamos la presencia de 5 fragmentos con decoración de boquique (1,5\%) (Figura 12, F) y 2 con campaniforme $(0,6 \%)$ (Figura $12, G)$.

\subsubsection{Tecnología}

\subsubsection{Tratamiento de las superficies}

El tratamiento exterior más frecuente es el alisado (56,2\% del inventario) seguido del bruñido $(41,7 \%)$ y de forma muy lejana de la barbotina $(1,5 \%)$, el espatulado y el cepillado $(0,1 \%$ respectivamente). Los ejemplares sin tratamiento o con superficies toscas presentan un escaso número $(1,6 \%)$.

\subsubsection{Cocciones}

Los indicios tecnológicos apuntan a un predominio de las cocciones reductoras $(71,2 \%)$ a las que hay que añadir un $10,2 \%$ que presentan alteraciones producidas por post-cocciones oxidantes. No obstante hay que señalar un mayor de cocciones irregulares (20,5\%) con respecto al Bronce antiguo. Los fragmentos con tonalidades naranjas correspondientes a ambientes oxidantes son muy escasos $(0,1 \%)$.

\subsubsection{Otros elementos cerámicos}

Se han individualizado algunas fichas (3) (Figura 13, A) y un posible fragmento de tapa (Figura 13, B).

\section{DISCUSIÓN}

Lo primero a tener en cuenta a la hora de valorar los materiales cerámicos recuperados en el yacimiento de El Portalón es la gran cantidad de restos cerámicos: constituye, de lejos, la familia mayor de la cultura material. Ello nos ha permitido, pese a la fragmentación con que se nos presenta, la realización de tablas formales tanto para el Bronce antiguo como para el Bronce medio, basadas en los perfiles de las piezas: en realidad, la reconstrucción de formas completas solo ha sido posible en ocho ocasiones (seis para la primera fase y dos para la segunda). Reconocemos que ha resultado también difícil precisar cómo son las particularidades del conjunto teniendo en cuenta la fragmentación anteriormente mencionada. A pesar de ello, no es difícil el cotejo de las producciones de ambos momentos con referencias a otros yacimientos, cercanos o no, de similar cronología, dado que estamos ante unas colecciones muy tipificadas en sus intereses.

La producción cerámica del grupo del Bronce antiguo se caracteriza por la elaboración de recipientes muy comunes: con profusión de vasos lisos, de tallas diversas, donde se aprecia el trabajo de decantación y amasado cuidado de la pasta, así como una preocupación por acabados pulcros. Solo en los vasos de mayores dimensiones las paredes pueden descuidarse, buscando intencionadamente superficies rugosas. Formalmente el género se ajusta a los llamados recipientes de mesa, cocina y almacenaje: a) cuencos semiesféricos, o en variantes más altas y cerradas o incluso de aire troncocónico; b) vasos de perfil en $\mathrm{S}$ que por representación son el segundo grupo en importancia: de cuello troncocónico, borde pequeño vuelto, paredes o rugosas -en los supuestos de almacenaje-, lisas o decoradas con digitaciones y ungulaciones en el borde y cordones impresos por debajo del cuello; c) no faltan

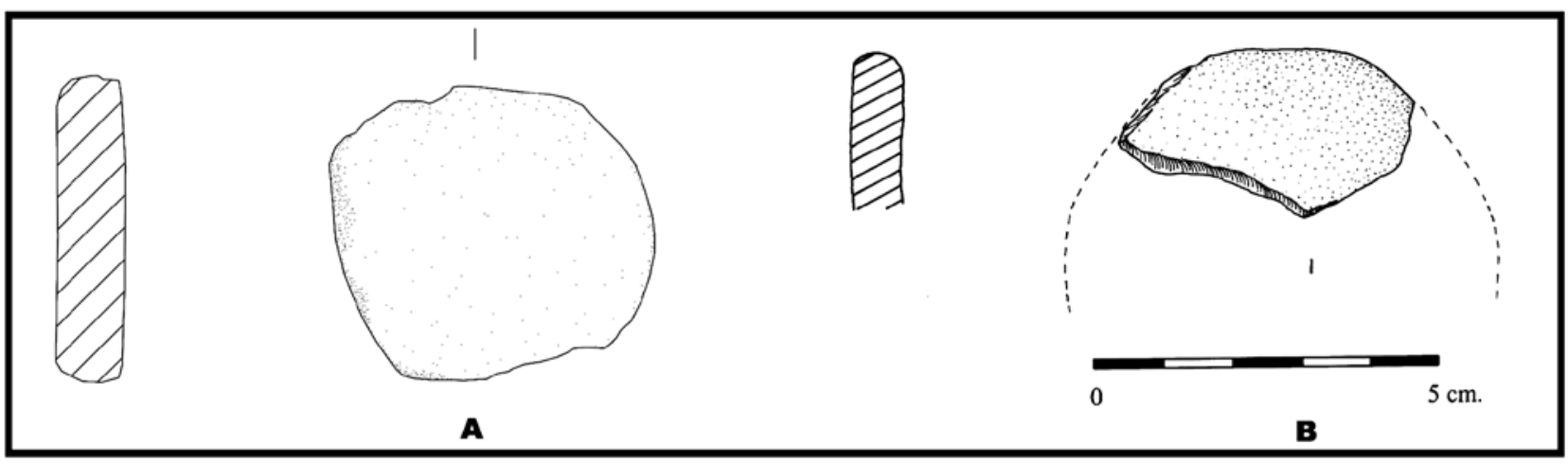

Fig. 13. A) Fichas; B) fragmento de tapa. / A) Counter; B) Fragment of a lid. 
los muy característicos recipientes carenados con el punto de inflexión a distintas alturas según variantes; d) completa la colección las típicas encellas vinculadas al aprovechamiento de productos secundarios.

Desde el punto de vista alfarero el Bronce medio representa una continuidad técnica y formal con el Bronce antiguo en el porcentaje de tipos y variantes, el tratamiento de las superficies, la profusión y estilo de las decoraciones y en la cocción. Quizá forzando los datos podríamos admitir un descenso de las formas abiertas, pero poco más. De nuevo dominan los cuencos, seguidos de los vasos de perfil en S, los carenados, las ollas globulares de borde exvasado, recto o reéntrate y las anecdóticas formas de tendencia cilíndrica. Las decoraciones, cortos trazos incisos o sencillas impresiones, repiten su distribución en labios, bajo el borde o acompañando a los añadidos plásticos: incisiones en espiga, zigzag aislados o agrupados, alguna retícula oblicua, triángulos con rayado interior e impresiones con los dedos.

Para el periodo del Bronce final, ya hemos señalado en la metodología que Apellániz estableció una secuencia con los tres niveles de la Edad del Bronce, antiguo, medio y final (APELLÁNIZ y DOMINGO, 1987) y que Mínguez (2005) presentó un estudio sobre el conjunto cerámico del Bronce final. Apellániz excavó El Portalón mediante la técnica de definir lechos sedimentarios. Nuestros estudios de sus memorias de excavación (depositas en el Museo de Burgos) y de sus diarios de campo (amablemente cedidos por él al mismo Museo), nos ha permitido cotejar la información espacial de cada pieza, incluyendo su cota, lo que nos ha permitido integrar sus piezas en nuestra nueva estratigrafía. Esto, junto con las nuevas dataciones radiocarbónicas realizadas posteriormente al estudio de Mínguez (CARRETERO et allí, 2008; PÉREZ-ROMERO et al., 2015a) y el estudio tipológico de las cerámicas nos ha permitido correlacionar los lechos arqueológicos definidos por Apéllaniz con los nuevos niveles estratigráficos definidos por el EIA (PÉREZ-ROMERO et al., 2015a). En base a todo ello proponemos una nueva lectura cronocultural que diferencia únicamente ocupaciones del Bronce inicial y medio, pero que hasta el momento no incluye ni materiales ni cronologías del Bronce final (PEREZ-ROMERO et al., 2015a). No podemos descartar, sin embargo, que este momento de la Prehistoria esté presente en otras zonas del yacimiento aún sin intervenir.

Desde el punto de vista tipológico y formal, el cortejo alfarero de El Portalón muestra una llamativa homogeneidad con independencia de su pertenencia a uno $\mathrm{u}$ otro nivel sedimentario y fase cultural: no variaron, al menos aparentemente, los patrones de producción a lo largo de los 700 años que nos ocupan, posiblemente porque se concibió bajo unos mismos criterios de funcionalidad, entendiéndose como un material que acompañaba en las tareas cotidianas de los grupos. Esa idea de uniformidad es tal que, salvo por cuestiones de detalle, rigen en El Portalón los mismos cánones que en dos yacimientos muy próximos, los también serranos de
El Mirador (MORAL et al., 2003-4; VERGES et al., 2002 y 2008) y la cueva de la Revilla (ABARQUERO et al., 2005). En los tres los inventarios se nos presentan considerablemente fragmentados, elaborándose sistemáticamente los recipientes a partir de pastas muy decantadas, con inclusiones de pequeño calibre, cocciones en atmósfera reductora que, aunque no falten los fragmentos de cochura irregular, muestran un dominio técnico suficiente -es especialmente cuidada la acción del fuego sobre los recipientes carenados-. Los artesanos se preocuparon por obtener productos de acabados exteriores e interiores finos, por alisado, bruñido, pulido... incluso, como se ha señalado, los elementos de paredes rugosas tienen una pensada intencionalidad.

La alta fragmentación de la cerámica, para todo el conjunto de la Edad del Bronce, complica la tipificación de los volúmenes y la descripción de sus variantes. Dado, como se ha expuesto, que los catálogos gravitan en torno a recipientes sencillos no es posible discriminar una evolución interna. Tampoco en la morfología de sus bordes, donde destacamos la alta frecuencia de los exvasados que estaríamos tentados a relacionar con las formas carenadas -pero los datos no permiten asegurar tal relación-. Los galbos muestran diferentes tallajes mientras que los fondos o los sistemas de prensión son poco significativos.

Escasa fue la inversión de los artesanos en la decoración de las vasijas. Aunque son abundantes los fragmentos decorados, para su realización se valieron fundamentalmente de sus manos -lo más usual serán las digitaciones y ungulaciones- y, ocasionalmente, de punzones de puntas simples. Proponen motivos sencillos que rara vez combinan en elaboradas sintaxis: aplican la incisión y la impresión sobre labios, bordes o el tercio superior de los volúmenes, a menudo sobre cordones plásticos-, en menos ocasiones se valen del esgrafiado o desarrollan motivos más complejos -algo de boquique o en la línea del campaniforme-. También en este sentido la constante es la norma entre los dos episodios de El Portalón.

Nada hay, pues, de singular en la producción cerámica de El Portalón durante la Edad del Bronce, donde el adjetivo sobrio es el que mejor la define. Como tal su paralelismo con colecciones contemporáneas es fácil de seguir: como expuso Abarquero (ABARQUERO et al., 2005) con ocasión del análisis de la alfarería de La Revilla, rescatar un listado de lugares arqueológicos del Valle del Duero con estas mismas características en sus cerámicas no dejaría de ser un ejercicio bastante lento y poco significativo. Podemos, así, valernos de su ejercicio, donde se citan los sitios burgaleses de: Las Veguillas, La Casa de la Villa de Villímar, el desfiladero de Pancorbo, el Abrigo de Río Losa, La Aceña en Lara de los Infantes, la cueva de San García y el castro de Yecla en Santo Domingo de Silos, Pico Romero I en Santa Cruz de la Salceda, Las Empedradas de Fuentecén, Carrasalinera en Roa de Duero, el Cerro de La Horra o Los Cascajos en Quintanadueñas, (RODRÍGUEZ y ARNÁIZ, 
1993; PALOMINO y ETCHEVERRIA, 1994; PALOMINO y RODRÍGUEZ, 1994 y 1997; PALOMINO et al., 1999). Y el listado puede ampliarse con referencias a enclaves de provincias limítrofes como: EL Carrizal, El Pico de Castro (RODRÍGUEZ, 2008) y El Cementerio-El Prado (RODRÍGUEZ y ABARQUERO, 1994) en Valladolid; La Cueva de Arevalillo (FERNÁNDEZ-POSSE, 1981) en Segovia; El Parpantique de Balluncar (JIMENO, 1988); Sector A y B de la Cueva del Asno (EIROA, 1979), Los Torojones de Morcuera (FERNÁNDEZ MORENO, 2013); El Pico de los Cotorros (BENITO et al., 2001) y Cueva Maja (SAMANIEGO et al., 2001) en Soria (Figura 1).

Que un grupo humano con estas señas de identidad conocía bien y explotaba con intensidad el entorno de la Sierra de Atapuerca nos lo confirma el yacimiento de El Portalón y su relación con los sitios de El Mirador, la Cueva de La Revilla, Las Fresas, San Polo y Santa Ana (MORAL et al., 2003-4; VERGÉS et al., 2002 y 2008); ABARQUERO et al., 2005) (Figura 1)

Estamos metidos de lleno en lo que, desde la cerámica, se titula como Protocogotas (DELIBES y FERNÁNDEZ ,1990; FERNÁNDEZ-POSSE, 1986 y, para el caso burgalés, RODRíGUEZ y ARNÁIZ, 1993) cuya formación debió tener lugar mediada la segunda mitad del segundo milenio a.C.

Entender el sentido de la producción, consumo y abandono de la colección cerámica de El Portalón durante la Edad del Bronce, pasa, irremediablemente, por la reflexión del por qué (y para qué) de las ocupaciones en cuevas por parte de unas sociedades, de la Edad del Bronce, que a la vez desarrollaban un potente hábitat al aire libre. ¿Cuáles son los ritmos de ocupación del recinto? ¿Permanente, temporal o intermitente? ¿En relación alguna funcionalidad muy específica? Y, en esta línea ¿cuál es la utilidad de la artesanía cerámica?

Lejos de ser la del El Portalón una situación particular, este modus vivendi se repite en otras estaciones de similares características: cuevas de gran tamaño, de ubicaciones más o menos serranas, con registro de una intensa actividad donde, a menudo, se combinan las acciones cotidianas con fórmulas funerarias más o menos elaboradas y, en el caso de El Portalón, con el añadido que suponen las ricas manifestaciones rituales-simbólicas de la llamada "Galería del sílex". Por ello, en la pretensión de contextualizar la Edad del Bronce de El Portalón, son de especial interés los registros arqueológicos situados en la misma Sierra, como los de EI Mirador (VERGÉS et allí., 2002 y 2008) y la Cueva de la Revilla (ABARQUERO et al., 2005): ya hemos visto en el apartado anterior que los tres lugares mantienen tales paralelismos en sus colecciones cerámicas que deben de concebirse dentro de una misma comunidad de intereses en su fabricación y consumo.

Los tres yacimientos coinciden, también, en el abandono de los recintos en la frontera de lo que ya se dice Bronce final (¿el final de un ciclo?), por más que se reconozcan ulteriores ocupaciones de la Protohistoria o de la Historia. Esta dinámica, repetida en otros confines ibéricos (citamos por su relativa cercanía los covachos de Los Husos I y II, San Cristóbal o Cueva Lóbrega en los rebordes montañosos del Ebro riojano) responde, en su génesis, desarrollo y declive a un pensado sistema de gestión socioeconómica muy ligado, probablemente, a la intensificación ganadera que se ha fijado en las serranías para el aprovechamiento de los pastos, y en los refugios espeleológicos para la reclusión de los rebaños y el asiento humano. En esta línea las referencias que hemos dado en el presente trabajo de la colección faunística de El Portalón (GALINDO-PELLICENA et al., 2014 , 2015) revela la importancia de las majadas domésticas desde el punto de vista económico. En este caso, entre el Bronce antiguo y el medio se han atisbado permutas en el peso relativo de las especies animales: más ovicaprinos en la fase antigua, más bovino en la reciente (GALINDO-PELLICENA et al., 2014, 2015). ¿Oportunidad de los datos o real cambio de intereses entre los grupos? En cualquier caso, lo que si se demuestra es el especial interés por la ganadería, como lo demuestra la presencia en estos niveles de un importante número de fumiers, tradicionalmente asociados a la quema del estiércol producido por el ganado, para el saneamiento de los recintos.

El objetivo principal de la gestión ganadera sería el aprovechamiento cárnico. La ausencia de patologías producidas por su uso para el tiro, la carga o la tracción avalaría esta interpretación. Pero si se desaprovecharían los huesos como materia prima para la elaboración de instrumentos (ALDAY et al., 2011, 2015; PÉREZ-ROMERO et al., 2015) y debe de valorarse el posible consumo de derivados de la leche: a ello respondería la presencia en la colección de las "queseras" cerámicas, útiles para la elaboración de productos lácteos almacenables, transportables y digestivos. Como queda de manifiesto tras los últimos estudios de ADN realizados en individuos del Portalón, los miembros de las Edades de los Metales eran intolerantes a la lactosa, pero si podían consumir derivados lácteos como el yogur o el queso (SVERRISDÓTTIR et al., 2014)

La ganadería se complementaría con la agricultura: el grano bien pudo almacenarse en esas vasijas toscas, de grandes dimensiones y paredes rugosas, comunes en la colección: la presencia de láminas y de dientes de hoz con pátinas de cereal y de molinos barquiformes estarían indicando el consumo de grano en la dieta de quienes vivían en El Portalón.

Concebimos la vida en la cavidad de El Portalón dentro de un circuito mayor, participando en una red posiblemente jerarquizada de yacimientos donde, además de lo indicado, también se consumía el producto de la caza -dentro de un visión integral del territorio y de sus posibilidades-, o donde se recepcionan no pocos productos de intercambio: materias primas -silíceas, minerales,...-, gasterópodos marinos, o productos originarios 0 inspirados en otros enclaves geográficos (ALDAY et al., 2015). 


\section{CONCLUSIONES}

Disponemos en El Portalón de una potente batería de fechas radiocarbónica (38 dataciones para la Edad del Bronce) que se van sucediendo, ordenadamente en profundidad y niveles, y sin solución de continuidad entre el 4200 y el 3500 cal BP. La ocupación es intensa a lo largo de esos 700 años, aunque en realidad la habitación había comenzado tiempo atrás y continuará después.

El volumen de materiales cerámicos recuperados es muy elevado (ronda los 35.000 elementos) y el nivel de fragmentación también. Por más que hayamos hecho una distinción en el interior de la Edad del Bronce no hay interrupción entre las fases, donde no se atisban cambios en los intereses de los grupos. Ello explicaría, la homogeneidad del inventario cerámico (y de en otros componentes materiales). Seguramente no sintieron la necesidad de modificar los patrones que organizaban la producción alfarera a lo largo de este tiempo, porque los intereses de las ocupaciones y la funcionalidad del repertorio alfarero no varió significativamente.

Hay que señalar que, en buena medida el uso de la cavidad durante la Edad del Bronce se relaciona con actividades pastoriles, en concordancia con una economía agropastoril dependiente de las actividades Ilevadas a cabo en poblados próximos. La Sierra de Atapuerca es un área zona propicia para la alimentación del ganado, y su explotación fue estable y duradera. Precisamente el volumen de la producción cerámica remarcaría dicha estabilidad habitacional, pero también la plurifuncionalidad del lugar: el inventario responde al desarrollo de actividades domésticas (ique escaso espacio y poca originalidad se deja al desarrollo del ornato de las vasijas!).

E indagando en otros contextos arqueológicos contemporáneos, se observa que la ocupación de El Portalón responde a un programa de largo alcance, donde la movilidad afectaba tanto a las personas como al ganado (ANDERUNG et al., 2005; GALINDO-PELLICENA, 2014) y a la propia cultura material: de ahí ese todo común regional, y la convivencia de intereses, que en El Portalón de Cueva Mayor, por su posición geográfica estratégica, vincula la Meseta Norte con el Alto Ebro, subrayando así la importancia de la Sierra de Atapuerca también en periodos avanzados del Holoceno.

\section{AGRADECIMIENTOS}

Nuestro más sincero agradecimiento a los muchos colegas y estudiantes que desde 2000 han hecho posible la excavación, restauración e inventario de las miles de piezas arqueológicas recuperadas de El Portalón y en especial a nuestros colegas del laboratorio de la Evolución Humana de la Universidad de Burgos y al equipo de Atapuerca. Muchas gracias a Marta Negro, Directora del Museo de Burgos por las facilidades ofrecidas para la consulta de los diferentes materiales.
Marta Francés-Negro disfruta de una beca de la Junta de Castilla y León (ORDEN/EDU1083/2013). Marian Galindo disfruta de una Beca Postdoctoral de la Fundación Atapuerca

Esta investigación ha sido financiada por el Ministerio de Ciencia e Innovación a través de Proyecto $n^{\circ}$ CGL2012-38434-C03-01 y el proyecto HAR-2011. Las excavaciones en los yacimientos de Atapuerca son financiadas por el Gobierno de la Junta de Castilla y León y la Fundación Atapuerca.

\section{BIBLIOGRAFÍA}

ABARQUERO, F.J., PALOMINO, A.L. y NEGREDO, M.J.

2005 La Cueva de la Revilla, un enterramiento colectivo del Bronce Protocogotas en la sierra de Atapuerca (Burgos). BSAA Arqueología LXXI, 89-136.

ALDAY, A., JUEZ, L., PÉREZ-ROMERO, A., ADÁN, G., SANTOS, E., GALINDO-PELLICENA, M.A., CARRETERO, J.M. y ARSUAGA, J.L.

2011 La industria ósea de El Portalón de Cueva Mayor (Sierra de Atapuerca, Burgos). Biapuntados, puntas de flecha y agujas, morfología y funcionalidad. Munibe Antropologia-Arkeologia 62, 227-249.

ALDAY, A., PÉREZ-ROMERO, A., CARRETERO, J.M., GALINDO-PELLICENA, M.A., ADÁN, G. y ARSUAGA, J.L.

2015 Proofs of Long-Distance Relations between Central Europe and Inland Iberian Peninsula during Neolithic and Bronze Age. Evidences from the Material Culture of the Site of El Portalón (Sierra de Atapuerca, Burgos, Spain). Advances in Anthropology 5, 294-32. Available on: http://www.scirp.org/journal/aa http://dx.doi. org/10.4236/aa.2015.54023

ANDERUNG, C., BOUWMAN, A. PERSSON, P., CARRETERO, J. M., ORTEGA, A. I., ELBURG, R., SMITH, C., ARSUAGA, J. L., ELLEGRN, $\mathrm{H}$. y GÖTHERSTRÖM, A.

2005 Prehistoric contacts over the Straits of Gibraltar indicated by genetic analysis of Iberian Bronze Age cattle. Proceeding of the National Academy of Sciences of the United States of America 102: 8431-8435.

APELLANIZ, J.M. y DOMINGO, D.

1987 Estudios sobre Atapuerca (Burgos): II. Los materiales de superficie del Santuario de la Galería del Sílex. Cuadernos de Arqueología de la Universidad de Deusto 10. Bilbao.

ARSUAGA, J.L., BERMÚDEZ DE CASTRO, J.M. y CARBONELL, E. (Eds)

1997 The Sima de los Huesos Hominid Site. Journal of Human Evolution, Special Issue 33, 105-421.

ARSUAGA, J.L., MARTINEZ, I., ARNOLD, L.J., ARANBURU, A., GRACIA-TELLEZ, A., SHARP, W.D., QUAM, R., FALGUERES, C., PANTOJA-PEREZ, A., BISCHOFF, J., POZA-REY, E., PARES, J.M., CARRETERO, J.M., DEMURO, M., LORENZO, C., SALA, N., MARTINON-TORRES, M., GARCIA, N., ALCAZAR DE VELASCO, A., CUENCA-BESCOS, G., GOMEZ-OLIVENCIA, A., MORENO, D., PABLOS, A., SHEN, C.-C., RODRIGUEZ, L., ORTEGA MARTINEZ, A.I., GARCIA, R., BONMMATI, A., BERMÚDEZ DE CASTRO, J.M. \& CARBONELL, E.

2014 Neandertal roots: Cranial and chronological evidence from Sima de los Huesos. Science 344, 1358-1363. 
ARSUAGA, J.L., CARRETERO, J.M., LORENZO, C., GOMEZ-OLIVENCIA, A., PABLOS, A., RODRIGUEZ, L., GARCIA-GONZÁLEZ, R., BONMATI, A., QUAM, R.M. PANTOJA-PEREZ, A., MARTINEZ, I., ARANBURU, A., GRACIA-TELLEZ, A., POZA-REY, E., SALA, N., GARCIA, N., ALCAZAR DE VELASCO, A., CUENCA-BESCOS, G., BERMUDEZ DE CASTRO, J.M. \& CARBONELL, E.

2015 Postcranial morphology of the middle Pleistocene humans from Sima de los Huesos, Spain. PNAS 112(37), 11524-11529.

BERMÚDEZ DE CASTRO, J.M., CARBONELL, E. \& ARSUAGA, J.L. (Eds.)

1999 Gran Dolina Site: TD6 Aurora Stratum (Burgos, Spain). Journal of Human Evolution, Special Issue 37.

BERMÚDEZ DE CASTRO, J.M., MARTINÓN-TORRES, M., GÓMEZ ROBLES, A., MARGVELASHVILI, A., ARSUAGA, J.L., CARRETERO, J.M., MARTÍNEZ, I. \& SARMIENTO, S.

2011 The Gran Dolina-TD6 Human Fossil Remains and the Origin of Neanderthals, in CONDEMI, S. \& WENIGER, G.C-. (Eds.). Continuity and Discontinuity in the Peopling of Europe: One Hundred Fifty Years of Neanderthal Study. Vertebrate Paleobiology and Paleoanthropology. Chapter 6, 76-75. Springer Science+Business Media B.V. 2011. ISBN: DOI 10.1007/978-94-007-0492-3-6.

BERMÚDEZ DE, CASTRO, J.M., MARTINÓN-TORRES, M., MARTÍN-FRANCÉS, L. MODESTO-MATA, M., MARTÍNEZ DE PINILLOS, M., GARCÍA, C. y CARBONELL, E.

2015 Homo antecessor: The state of the art eighteen years later. Quaternary International http://dx.doi.org/10.1016/j. quaint.2015.03.049

BENITO, J.P., SANZ, A. y TABERNERO, C.

2001 Excavación arqueológica en "El Pico de los Cotorros". Langa de Duero (Soria). Informe técnico. Areco, Junta de Castilla y León. Inédito.

CARRETERO, J.M., ORTEGA, A.I., JUEZ, L., PÉREZ-GONZÁLEZ, A., ARSUAGA. J.L., PÉREZ, R. y ORTEGA, M.C.

2008 A Late Pleistocene-Early Holocene archaeological sequence of Portalón de Cueva Mayor (Sierra de Atapuerca, Burgos, Spain). Munibe Antropologia-Arkeologia $5,67-80$.

CLARK, G., STRAUS, L.G., BURTON, S.S. y JACKSON-CLARK, V.

1979 The North Burgos Archaelogical Survey: An inventory of cultural remains, in CLARK, G. (Ed.). The North Burgos Archaelogical Survey. Bronze and Iron Age archaeology on the Meseta del Norte (Province of Burgos, North-Central Spain) 19, 18 156. Arizona State University. Dept. of Antropology.

CUBAS, M

2013 La aparición de la tecnología cerámica en la región cantábrica. BAR International Series 2566. Archaeopress. Oxford.

DELIBES, G., FERNÁNDEZ, J. y RODRÍGUEZ, J.A

1990 Cerámica de la plenitud de Cogotas I: El yacimiento de San Román de Hornija (Valladolid). Boletín del Seminario de estudios de Arte y Arqueología LVI, 64-105.

EIROA, J.J.

1979 La Cueva del Asno. Los Rábanos (Soria). Campaña 19761977. Excavaciones Arqueológicas de España, 107.
FERNÁNDEZ MORENO, J.J.

2013 El Bronce antiguo en el oriente de la Submeseta norte. El inicio de la Edad del Bronce en el Alto Duero: el Horizonte Parpantique. Tesis Doctoral. Universidad Complutense de Madrid. Facultad de Geografía e Historia. Departamento de Prehistoria.

FERNÁNDEZ-POSSE, M.D.

1981 La Cueva del Arevalillo (Segovia). Noticiario Arqueológico Hispánico 12, 45-84.

1986 La Cultura de Cogotas I, en Homenaje a Luis Siret (1934-1984). 475-487. Sevilla.

\section{GALINDO-PELLICENA, M.A.}

2014 Estudio de la macrofauna de los niveles holocenos del yacimiento de El Portalón (Sierra de Atapuerca, Burgos). Universidad Complutense de Madrid. Facultada de Ciencias Geológicas. Departamento de Paleontología. Tesis Doctoral. Inédita.

GALINDO-PELLICENA, M.A., PÉREZ-ROMERO, A., FRANCÉS-NEGRO, M., ÁlV́AREZ, A., IRIARTE, E., ARSUAGA, J.L. \& CARRETERO, J.M.

2015 The equids from the Bronze Age levels of the El Portalón site (Atapuerca, Burgos, Spain). Quaternary International. http://dx.doi.org/10.1016/j.quaint.2015.11.120.

GÜNTHER, T., VALDIOSERA, C., MALMSTRÖM, H., UREÑA, I., RODRÍGUEZZ-VARELA, R., SVEERRISDÓTTIR, O.O., DASKALAKI, E.A., SKOGLUND, P., NAIDOO, T., SVENSSON, E.M., BERMÚDEZ DE CASTRO, J.M.., CARBÓNELLL, E., DUNN, M., STORA, J., IRIARTE, E., ARSUAGA, J.L., CARRETERO, J.M., GÖTHERSTRÖM, A. \& JAKOBSSON, M.

2015 Ancient genomes link early farmers from Atapuerca in Spain to modern-day Basques. PNAS, 112(38), 1191711922.

JOVER, F.J. Y LÓPEZ, J.A.

2013 La producción textil durante la Edad del Bronce en el cuadrante Suroriental de la Península Ibérica: materias primas, productos, instrumentos y procesos de trabajo. Zephyrus LXXI, 149-171.

JIMENO, A., FERNÁNDEZ, J.J. y REVILLA M.L.

1988 Asentamientos de la edad del Bronce en la provincia de Soria: Consideraciones sobre los contextos culturales del Bronce antiguo. Noticiario Arqueológico Hispano $30,83-119$

LLANOS, A. y VEGAS, J.I.

1974 Ensayo de un método para el estudio y clasificación tipológica de la cerámica. Estudios de Arqueología Alavesa VI, 265-313.

MAYA, J.L. y PETÍT, M.A.

1986 El grupo del Nordeste. Un nuevo conjunto de cerámicas con boquique en la Península Ibérica. Anales de Prehistoria y Arqueología 2, 49-71.

MÍNGUEZ, M.T.

2005 Los materiales del Bronce Final de "El Portalón" de Cueva Mayor. Estudios sobre Atapuerca (Burgos) III. Cuadernos de Arqueología, vol. 20.

MORAL, S., RODRÍGUEZ, J.A. y DIEZ, J.C.

2003-2004 Las cerámicas de la Cueva del Mirador (Ibeas de Juarros, Burgos) en el contexto del Bronce medio de la Submeseta norte. BSSA 69-70, 57-74. 
ORTEGA, A.I.

2009 La evolución geomorfológica del Karst de la sierra de Atapuerca (Burgos) y su relación con los yacimientos pleistocenos que contiene. Tesis Doctoral inédita. Universidad de Burgos.

PALOMINO, A.L. y ETCHEVERRIA, C.

1994 Informe técnico sobre la excavación arqueológica realizada en el yacimiento de la Edad del Bronce "Pico Romero I" Santa Cruz de la Salceda (Burgos). Junta de Castilla y León. Universidad de Valladolid. Inédito.

PALOMINO, A.L. y RODRÍGUEZ, J.A.

1994 El yacimiento arqueológico de Las Empedradas: un enclave del Bronce medio en la ribera del Duero burgalesa. Nvmantia Arqueología en Castilla y León 5, 59-71.

1997 Un asentamiento castreño del Bronce antiguo en la cuenca del Duero: el Pico Romero en Santa Cruz de la Salceda (Burgos). II Congreso de Arqueología Peninsular, Zamora. Vol. 2: 249-256.

PALOMINO, A.L., NEGREDO, M.J., ABAD, I. y ABARQUERO, F.J.

1999 Cabañas, basureros, silos y tumbas en el yacimiento del Cerro, La Horra (Burgos): a vueltas sobre el significado de un campo de hoyos de la Edad del Bronce en la Meseta. Nvmantia, Arqueología en Castilla y León 7, 21-41.

PÉREZ-ROMERO, A., CARRETERO, J.M., JUEZ, L., ORTEGA, A.I., ORTEGA, M.C. y ARSUAGA, J.L.

2010 Una dobla almohade del siglo XIII en el yacimiento de El Portalón de Cueva Mayor, Sierra de Atapuerca (Burgos). Nvmisma 254, 85-106.

PÉREZ-ROMERO, A., CARRETERO, J.M., ALDAY, A. y ARSUAGA, J.L.

2013 La Cerámica Protohistórica e Histórica en el yacimiento de El Portalón de Cueva Mayor, Sierra de Atapuerca, Burgos. Boletín de la Sociedad Española de Cerámica y Vidrio 52 (4), 183-193.

PÉREZ-ROMERO, A., CARRETERO, J.M., ALDAY, A., GALINDO-PELLICENA, M.A., ADÁN, G., JÜEZ, L. y ARSUUAGA, J.L.

2015a La gestión del utillaje óseo de la Edad del Bronce en el yacimiento de El Portalón de Cueva Mayor, sierra de Atapuerca, Burgos. Complutum 26(1), 113-131.

PÉREZ-ROMERO, A., IRIARTE, E., GALINDO-PELLICENA, M.A., GARCÍA-GONZÁLES, R., RODRÍGUEZ, L., CASTILLA, M., FRANCÉS-NEGRO, M., SANTOS, E., VALDIOSERA, C., ARSUAAGA, J.L., ALDAY, A. y CARRETERO, J.M.

2015b An unusual Pre-bell beaker copper age cave burial context from El Portalón de Cueva Mayor site (Sierra de Atapuerca, Burgos). Quaternary International . http:// dx.doi.org/10.1016/j.quaint.2015.06.063.

PICAZO, J.V.

1993 La Edad del Bronce en el sur del Sistema Ibérico Turolense, I: Los materiales cerámicos. Monografías arqueológicas del S.A.E.T. 7. Seminario de Arqueología y Etnología Turolense, Teruel.

\section{RODRÍGUEZ MARCOS, J.M.}

2008 Estudio secuencial de la edad del Bronce en la Ribera del Duero (provincia de Valladolid). Monografías. Arqueología en Castilla y León, 7 . Junta de castilla y León. Consejería de Cultura y Turismo.
RODRÍGUEZ, J.M., y ARNAIZ, M.A.

1993 Los primeros metalúrgicos en Burgos. Historia 16 de Burgos T.I fasc. 7, 33-38.

RODRÍGUEZ, J.M., y ABARQUERO, F.J

1994 Intervención arqueológica en el yacimiento de la Edad del Bronce de "El Cementerio-El Prado" Quintanilla de Onésimo (Valladolid). Nvmantia, Arqueología en Castilla y León 5, 33-38.

ROJO, M.A., PEÑA, L., ROYO, J.I., TEJEDOR, C., GARCÍA-MARTÍNEZ DE LAGRÁN, I., ARCUSA, H., GARRIDO, R., MORENO, M., MAZZUCCO, N., GIBAJA, J.F., ORTEGA, D., KROMER, B. y ALT, K.W.

2013 Pastores trashumantes del Neolítico antiguo en un entorno de alta montaña: secuencia crono-cultural de la Cova de Els Trocs (San Feliú de Veri, Huesca). BSAA Arqueología 79, 9-55.

SAMANIEGO, B., JIMENO, A., FERNÁNDEZ, J.J. y GÓMEZ, J.A.

2001 Cueva Maja (Cabrejas del Pinar, Soria): Espacio y simbolismo en los inicios de la Edad del Bronce. Arqueología en castilla y León. Memorias 10. Valladolid.

SVERRISDÓTTIR, Ó., TIMPSON, A., TOOMBS, J., LECOEUR, C., FROGUEL, P., CARRETERO J.M., ARSUAGA, J.L., ANDERS GÖTHERSTRÖM, A. y THOMAS, M.G.

2014 Direct Estimates of Natural Selection in Iberia Indicate Calcium Absorption Was Not the Only Driver of Lactase Persistence in Europe. Molecular Biology and Evolution. Advance Access published January 21. Available on: http://mbe.oxfordjournals.org/content/ early/2014/01/20/molbev.msu049.full.pdf+html

VERGÉS, J.M., ALLUÉ, E., ANGELUCCí, D.E., CEBRIÁ, A., FONTANALS, M.D., MÁNYANOS, A., MONTERO, S., MORAL, S., VAQUERO, M. y ZARAGOZA, J.

2002 La sierra de Atapuerca durante el Holoceno: datos preliminares sobre las ocupaciones de la Edad del Bronce en la cueva de Mirador (Ibeas de Juarros, Burgos). Trabajos de Prehistoria 59, 107-126.

VERGÉS, J.M., ALLUÉ, E., ANGELUCCÍ, D.E., BURJACHS, F., CARRANCHO, A., CEBRIA, A., EXPÓSITO, I., FONTANALS, M., MORAL, S., RODRÍGUEZ, A. Y VAQUERO, M.

2008 Los niveles neolíticos de la cueva del Mirador (Sierra de Atapuerca, Burgos): nuevos datos sobre la implantación y el desarrollo de la economía agropecuaria en la submeseta norte, en HERNÁNDEZ, M.S. y LÓPEZ, J.A. (Eds.). IV congreso del Neolítico Peninsular. 418427. MARQ, Museo Arqueológico de Alicante. Diputación de Alicante. 